\title{
Procedures for Labeling the High-Resolution Axis of Two-Dimensional MQ-MAS NMR Spectra of Half-Integer Quadrupole Spins
}

\author{
Yannick Millot and Pascal P. Man
}

\begin{abstract}
Systèmes Interfaciaux à l'Echelle Nanométrique, CNRS FRE 2312,
Laboratoire de Chimie des Surfaces, Université Pierre et Marie Curie, 4 Place Jussieu, Casier 196, Tour 55, 75252 Paris Cedex 05, France

E-mail: pm@ccr.jussieu.fr
\end{abstract}

Received May 7, 2001; revised September 10, 2001; published online February 19, 2002

\begin{abstract}
The increasing development and application of the multiple-quantum MAS NMR for halfinteger quadrupole spins has led to various RF pulse sequences for improving the excitation of multiple-quantum coherences and their conversion to single-quantum coherences. As a result, several conventions for labeling the F1 dimension of a 2D MQ-MAS spectrum appear in the literature. The corresponding relations for extracting the isotropic chemical shift, the quadrupole coupling constant, and the asymmetry parameter from experimental data are not always provided. We analyze these various conventions systematically and propose a new one, similar to that introduced by J.-P. Amoureux and C. Fernandez (2000, Solid State NMR 10, $339-343)$. These various conventions are illustrated with ${ }^{27} \mathrm{Al}(I=5 / 2)$ nuclei in aluminum acetylacetonate $\mathrm{Al}\left(\mathrm{CH}_{3} \mathrm{COCHCOCH}_{3}\right)_{3}$. Another experimental problem often met, the aliasing of peaks in the $2 \mathrm{D}$ spectrum, is analyzed and illustrated with ${ }^{27} \mathrm{Al}(I=5 / 2)$ in $\mathrm{NH}_{4} \mathrm{Y}$ zeolite and ${ }^{23} \mathrm{Na}(I=3 / 2)$ in sodium pyrophosphate $\mathrm{Na}_{4} \mathrm{P}_{2} \mathrm{O}_{7}$. ๑ 2002 Elsevier Science (USA)
\end{abstract}

Key Words: MQ-MAS; half-integer quadrupole spin; spectrum aliasing.

\section{INTRODUCTION}

Multi-quantum magic-angle spinning (MQ-MAS) spectroscopy on half-integer quadrupole spins, introduced by Frydman and Harwood [1], has become a routine technique for counting the number of crystallographic sites in a compound. The increasing number of papers published since 1995 evidences its impact on the NMR community. The various subjects dealt with can be separated into two groups: the improvement of the method and its application to material science.

Since MQ-MAS is a 2D experiment, the first development concerns the sensitivity enhancement of the 2D spectrum. Various radiofrequency (RF) pulse sequences have been suggested [2-20], including shaped pulses [21, 22], optimization of MQ coherence transfers [23-25], factors limiting the resolution [26-30], spectral editing [31], correlation between satellite and central transitions [32], suppression of sidebands by variable-speed MAS [33], spectra simulation [34-36], quantification of spectra with numerical simulation [37], lineshape analysis [38-40], and disorder analysis [41]. 
This method has been applied to the characterization of: (i) meso- and microporous materials such as alumina [42], aluminophosphate [11, 12, 43-47], aluminosilicate [48-50], phosphoro-vanado-alumina [51], or titanosilicate ETS-10 [52]; (ii) zeolites such as dealuminated beta [53], cancrenite [54], chabazite [55], mazzite [56], dealuminated offretite [57], SAPO37 [58], $\mathrm{NaX}$ and $\mathrm{NaY}[59,60]$, steamed $\mathrm{Y}$ [61-63], or dehydrated H-ZSM5 [64]; (iii) minerals such as sodium pyrophosphate $\mathrm{Na}_{4} \mathrm{P}_{2} \mathrm{O}_{7}$ [65-67] and $\mathrm{Na}_{5} \mathrm{P}_{3} \mathrm{O}_{10}$ [68], $\mathrm{SrAl}_{12} \mathrm{O}_{19}$ [69], andalusite [70, 71], forsterite $\mathrm{Mg}_{2} \mathrm{SiO}_{4}$ [72], kaolinite [73], kyanite [70, 71], zoisite [74], lanthanum-aluminate [75], calcium silicate hydrate [76, 77], or layered double hydroxide [78]; (iv) complex molecules such as $\left[\mathrm{d}\left(\mathrm{TG}_{4} \mathrm{~T}\right)\right]_{4}$ [79], antibiotic ionophore [80], nucleic acid [81], or ligand disordering [82]; (v) glasses such as aluminoborate [83], sodium aluminoborate [84], magnesium aluminoborate [85], aluminoborosilicate [86], aluminosilicate [87, 88], boroaluminate [89], solid electrolyte [90], or disorder in glasses [91, 92]; and (vi) phase transition in inorganic rubidium salts [93]. Despite the numerous papers quoted above and published from 1998, little attention has been paid to the labeling of the F1 axis of the 2D MQ-MAS spectrum. Knowing the observed chemical shifts of the center of gravity of a peak in the two dimensions allows us to extract the isotropic chemical shift $\delta_{\mathrm{CS}}^{\text {iso }}$ and the second-order quadrupole shift $\omega_{-1 / 2,1 / 2}^{(2) \text { iso }}$ of the peak. These two parameters characterize the local symmetry of a crystallographic site in solids [94].

In this paper, we present the various conventions which have appeared in the literature for labeling the F1 axis and analyze, from a practical point of view, their advantages and disadvantages. The reader should not been disturbed by the no-standard nomenclatures used by us for these conventions. Only results concerning sheared spectra are presented, postponing those about unsheared spectra to future work. We also take this opportunity to consider the aliasing of peaks in a 2D MQ-MAS spectrum, which generates wrong observed chemical shift values. For this purpose, the ${ }^{27} \mathrm{Al}(I=5 / 2)$ nuclei in aluminum acetylacetonate $\mathrm{Al}\left(\mathrm{CH}_{3} \mathrm{COCHCOCH}_{3}\right)_{3}$ are used to illustrate the various conventions. The ${ }^{27} \mathrm{Al}$ $(I=5 / 2)$ nuclei in $\mathrm{NH}_{4}$-Y zeolite and ${ }^{23} \mathrm{Na}(I=3 / 2)$ nuclei in sodium pyrophosphate $\mathrm{Na}_{4} \mathrm{P}_{2} \mathrm{O}_{7}$ are used to illustrate the peak aliasing in a 2D MQ-MAS spectrum. In the first two compounds, there is only one crystallographic site for aluminum nuclei. On the other hand, four crystallographic sites are available for sodium nuclei in the last compound.

\section{THEORY}

In its simplest form, the RF pulse sequence associated with MQ-MAS consists of a two-pulse spin-echo sequence. The delay $t_{1}$ between the two RF pulses is called the experimental evolution period or MQ evolution period. The experimental acquisition period $t_{2}$ starts from the end of the second pulse (Fig. 1a). The echo signal is located at $t_{2}=|k(I, p)| t_{1}[1,95-99]$ and the anti-echo signal at $t_{2}=-|k(I, p)| t_{1}$, $p$ being the coherence order. Furthermore, the MQ coherence, generated by the first RF pulse and refocused by the second RF pulse as echo, and that refocused as anti-echo have opposite coherence orders. Contrary to the conventional Hahn 


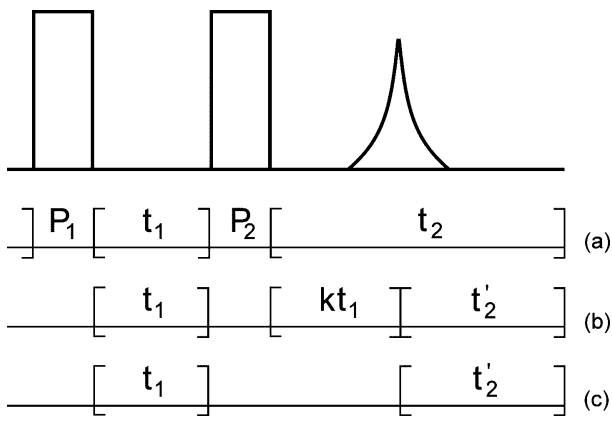

FIG. 1. Various meanings of the time-domain parameters. (a) Standard notations used in the twopulse MQ-MAS experiment: $t_{1}$ and $t_{2}$ are the experimental evolution and the experimental acquisition periods, respectively. $P 1$ and $P 2$ are the pulse durations. (b) Notations involved in conventions $C_{k(1)}, C_{k(2)}, C_{3 b(1)}, C_{3 b(2)}, C_{4 b(1)}, C_{4 b(2)}, C_{5 b(1)}$, and $C_{5 b(2)}$; the position of the echo relative to the first RF pulse $(1+k) t_{1}$ is the evolution period and $t_{2}^{\prime}$ is the shifted-acquisition period after the shearing transformation. (c) Notations involved in conventions $C_{z}, C_{3 a}, C_{4 a}$, and $C_{5 a}$; the MQ evolution period $t_{1}$ is the evolution period and $t_{2}^{\prime}$ is the shifted-acquisition period after the shearing transformation. Convention $C_{z}$ is used by Medek and co-workers (Ref. [96]) and Hanaya and Harris (Ref. [106]); $C_{k(1)}$ and $C_{k(2)}$ by Massiot and co-workers (Ref. [97]) and Wang and co-workers (Ref. [111]); $C_{3 a}, C_{3 b(1)}$, and $C_{3 b(2)}$ by Amoureux and Fernandez (Refs. [23, 24]); $C_{4 a}, C_{4 b(1)}$, and $C_{4 b(2)}$ by Bodart and co-workers (Ref. [50]); $C_{5 a}, C_{5 b(1)}$, and $C_{5 b(2)}$ by ourselves.

echo [100-104], which is located at $t_{2}=t_{1}$ and whose amplitude is modulated neither in phase nor in amplitude, the MQ-MAS echo and anti-echo amplitudes are phase-modulated by $\exp \left[-t_{2} \omega_{\mathrm{F} 1}(I, p)\right]$ with [105]

$$
\omega_{\mathrm{F} 1}(I, p)=[k(I, p)-p] \omega_{\mathrm{cf}} \delta_{\mathrm{CS}}^{\text {iso }}+[k(I, p)+\lambda(I, p)] \omega_{-1 / 2,1 / 2}^{(2) \text { iso }},
$$

$\omega_{\mathrm{cf}}$ being the carrier frequency of the spectrometer. The quantity $\lambda(I, p)$ relates the second-order quadrupole shift $\omega_{p / 2,-p / 2}^{(2) \text { iso }}$ of a $p Q$ spectrum to that of a $-1 Q$ spectrum, $\omega_{-1 / 2,1 / 2}^{(2) \text { iso }}$, as

$$
\omega_{p / 2,-p / 2}^{(2) \text { iso }}=\lambda(I, p) \omega_{-1 / 2,1 / 2}^{(2) \text { iso }},
$$

with

$$
\begin{gathered}
\omega_{-1 / 2,1 / 2}^{(2) \text { iso }}=-\frac{3\left(2 \pi C_{Q \eta}\right)^{2}}{10 \omega_{\mathrm{cf}}[2 I(2 I-1)]^{2}}\left[I(I+1)-\frac{3}{4}\right], \\
C_{Q \eta}=\frac{e^{2} q Q}{h} \sqrt{1+\frac{1}{3} \eta^{2}}=C_{Q} \sqrt{1+\frac{1}{3} \eta^{2}} .
\end{gathered}
$$

The values of $k$ and $\lambda$ for the four half-integer quadrupole spins $I$ and the coherence order $p$ are reported in Table 1 . The parameters $C_{Q \eta}$ and $C_{Q}$ are called the quadrupole product and the quadrupole coupling constant, respectively. Conversely, 


\section{TABLE 1}

Parameters (Spin $I$, Coherence Order $p$, Echo Position $k$, and $\lambda$ in Eq. (2)) Related to Various Conventions

\begin{tabular}{|c|c|c|c|c|c|c|c|c|c|c|c|c|}
\hline \multirow[b]{2}{*}{$I$} & \multirow[b]{2}{*}{$p$} & \multirow[b]{2}{*}{$k$} & \multirow[b]{2}{*}{$\lambda$} & \multicolumn{3}{|c|}{$\begin{array}{c}\text { Medek } \\
\text { Ref. [96] }\end{array}$} & \multicolumn{3}{|c|}{$\begin{array}{l}\text { Massiot } \\
\text { Ref. [97] }\end{array}$} & \multicolumn{3}{|c|}{$\begin{array}{c}\text { Bodart } \\
\text { Ref. [50] }\end{array}$} \\
\hline & & & & $\begin{array}{r}k_{1 z} \\
k-p \\
\end{array}$ & $\begin{array}{c}k_{2 z} \\
k+\lambda\end{array}$ & $\begin{array}{l}k_{G z} \\
\frac{-1}{p+\lambda} \\
\end{array}$ & $\begin{array}{l}k_{1 k} \\
\frac{k-p}{1+k} \\
\end{array}$ & $\begin{array}{l}k_{2 k} \\
\frac{k+\lambda}{1+k} \\
\end{array}$ & $\begin{array}{c}k_{G k} \\
-\frac{1+k}{p+\lambda} \\
\end{array}$ & $\begin{array}{l}k_{14} \\
\frac{k-p}{p} \\
\end{array}$ & $\begin{array}{l}k_{24} \\
\frac{k+\lambda}{p} \\
\end{array}$ & $\begin{array}{l}k_{G 4} \\
\frac{-p}{p+\lambda} \\
\end{array}$ \\
\hline$\frac{3}{2}$ & -3 & $\frac{7}{9}$ & -3 & $\frac{34}{9}$ & $-\frac{20}{9}$ & $\frac{1}{6}$ & $\frac{17}{8}$ & $-\frac{5}{4}$ & $\frac{8}{27}$ & $-\frac{34}{27}$ & $\frac{20}{27}$ & $-\frac{1}{2}$ \\
\hline$\frac{5}{2}$ & 3 & $\frac{19}{12}$ & $-\frac{3}{4}$ & $-\frac{17}{12}$ & $\frac{5}{6}$ & $-\frac{4}{9}$ & $-\frac{17}{31}$ & $\frac{10}{31}$ & $-\frac{31}{27}$ & $-\frac{17}{36}$ & $\frac{5}{18}$ & $-\frac{4}{3}$ \\
\hline & -5 & $\frac{25}{12}$ & $-\frac{25}{4}$ & $\frac{85}{12}$ & $-\frac{25}{6}$ & $\frac{4}{45}$ & $\frac{85}{37}$ & $-\frac{50}{37}$ & $\frac{37}{135}$ & $-\frac{17}{12}$ & $\frac{5}{6}$ & $-\frac{4}{9}$ \\
\hline$\frac{7}{2}$ & 3 & $\frac{101}{45}$ & $-\frac{9}{5}$ & $-\frac{34}{45}$ & $\frac{4}{9}$ & $-\frac{5}{6}$ & $-\frac{17}{73}$ & $\frac{10}{73}$ & $-\frac{73}{27}$ & $-\frac{34}{135}$ & $\frac{4}{27}$ & $-\frac{5}{2}$ \\
\hline & 5 & $\frac{11}{9}$ & 1 & $-\frac{34}{9}$ & $\frac{20}{9}$ & $-\frac{1}{6}$ & $-\frac{17}{10}$ & 1 & $-\frac{10}{27}$ & $-\frac{34}{45}$ & $\frac{4}{9}$ & $-\frac{5}{6}$ \\
\hline & -7 & $\frac{161}{45}$ & $-\frac{49}{5}$ & $\frac{476}{45}$ & $-\frac{56}{9}$ & $\frac{5}{84}$ & $\frac{238}{103}$ & $-\frac{140}{103}$ & $\frac{103}{378}$ & $\begin{array}{r}-\frac{68}{45} \\
\end{array}$ & $\frac{8}{9}$ & $-\frac{5}{12}$ \\
\hline$\frac{9}{2}$ & 3 & $\frac{91}{36}$ & $-\frac{9}{4}$ & $-\frac{17}{36}$ & $\frac{5}{18}$ & $-\frac{4}{3}$ & $-\frac{17}{127}$ & $\frac{10}{127}$ & $-\frac{127}{27}$ & $-\frac{17}{108}$ & $\frac{5}{54}$ & -4 \\
\hline & 5 & $\frac{95}{36}$ & $-\frac{5}{4}$ & $-\frac{85}{36}$ & $\frac{25}{18}$ & $-\frac{4}{15}$ & $-\frac{85}{131}$ & $\frac{50}{131}$ & $-\frac{131}{135}$ & $-\frac{17}{36}$ & $\frac{5}{18}$ & $-\frac{4}{3}$ \\
\hline & 7 & $\frac{7}{18}$ & $\frac{7}{2}$ & $-\frac{119}{18}$ & $\frac{35}{9}$ & $-\frac{2}{21}$ & $-\frac{119}{25}$ & $\frac{14}{5}$ & $-\frac{25}{189}$ & $-\frac{17}{18}$ & $\frac{5}{9}$ & $-\frac{2}{3}$ \\
\hline & -9 & $\frac{31}{6}$ & $-\frac{27}{2}$ & $\frac{85}{6}$ & $-\frac{25}{3}$ & $\frac{2}{45}$ & $\frac{85}{37}$ & $-\frac{50}{37}$ & $\frac{37}{135}$ & $-\frac{85}{54}$ & $\frac{25}{27}$ & $-\frac{2}{5}$ \\
\hline
\end{tabular}

$C_{Q \eta}$ can be expressed by

$$
C_{Q \eta}=A_{Q \eta} \sqrt{-\frac{\omega_{-1 / 2,1 / 2}^{(2) \text { iso }}}{\omega_{\mathrm{cf}}}},
$$

with

$$
A_{Q \eta}=I(2 I-1) \frac{\omega_{\mathrm{cf}}}{2 \pi} \sqrt{\frac{40}{3\left[I(I+1)-\frac{3}{4}\right]}} .
$$

If the acquisition of the data starts at the position $t_{2}=k t_{1}$ of the echo, the position $\omega_{\mathrm{F} 1}(I, p)$ of the peak relative to the carrier frequency in the $\mathrm{F} 1$ dimension is given by Eq. (1). To express this position in chemical shift units, it is necessary to divide Eq. (1) by a spectrometer frequency.

The obvious choice is the carrier frequency $\omega_{\text {cf }}$ of the spectrometer. This way of labeling the F1 dimension of the MQ-MAS spectra has been applied by Medek and co-workers [96] and Hanaya and Harris [106]. We called it convention $C_{z}$ previously [105] and denoted the observed chemical shift of the center of gravity of the peak in the $\mathrm{F} 1$ dimension by

$$
\delta_{G 1-z}^{\mathrm{obs}}=\frac{\omega_{\mathrm{F} 1}(I, p)}{\omega_{\mathrm{cf}}} .
$$

The second choice of the carrier frequency is $p \omega_{\text {cf }}$, the frequency related to a $p Q$ transition. We call it convention $C_{4 a}$, which has been used by Bodart and 
co-workers [50]. Since $p \omega_{\text {cf }}$ is not real, it is called the apparent carrier frequency and the observed chemical shift of the center of gravity of the peak in the F1 dimension is defined by

$$
\delta_{G 1-4 a}^{\mathrm{obs}}=\frac{\omega_{\mathrm{F} 1}(I, p)}{p \omega_{\mathrm{cf}}}=\frac{1}{p} \delta_{G 1-z}^{\mathrm{obs}} .
$$

The third choice of the apparent carrier frequency is $(k-p) \omega_{\mathrm{cf}},(k-p)$ being the factor of $\omega_{\mathrm{cf}} \delta_{\mathrm{CS}}^{\text {iso }}$ in Eq. (1). We call it convention $C_{3 a}$, which was introduced by Amoureux and Fernandez [23, 24]. The observed chemical shift of the center of gravity of the peak in the F1 dimension is defined by

$$
\delta_{G 1-3 a}^{\mathrm{obs}}=\frac{\omega_{\mathrm{F} 1}(I, p)}{(k-p) \omega_{\mathrm{cf}}}=\frac{1}{k-p} \delta_{G 1-z}^{\mathrm{obs}} .
$$

We propose a new choice of the apparent carrier frequency, namely

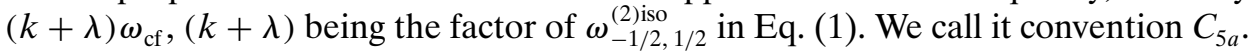
The observed chemical shift of the center of gravity of the peak in the F1 dimension is defined by

$$
\delta_{G 1-5 a}^{\mathrm{obs}}=\frac{\omega_{\mathrm{F} 1}(I, p)}{(k+\lambda) \omega_{\mathrm{cf}}}=\frac{1}{k+\lambda} \delta_{G 1-z}^{\mathrm{obs}} .
$$

The above conventions consider the MQ evolution period $t_{1}$ as the evolution period (Fig. 1c). The second way to define the evolution period is to consider the position of the echo relative to the first RF pulse (Fig. 1b). In other words, the evolution period becomes $(1+k) t_{1}$. Since the chemical-shift range in the F1 dimension is given by the ratio of the experimental spectral width $S W(\mathrm{~F} 1)$ to the apparent carrier frequency, the factor $(1+k)$ should affect either $S W(\mathrm{~F} 1)$ or the apparent carrier frequency. Therefore, this new definition of the evolution period leads to two ways for labeling the F1 axis but giving the same chemical-shift range:

(i) We modify the increment $\Delta t_{1}$ of the experimental evolution period by $(1+k) \Delta t_{1}$, but keep the apparent carrier frequencies of the above conventions $\left(C_{z}, C_{4 a}, C_{3 a}\right.$, and $\left.C_{5 a}\right)$ unchanged. The increment $\Delta t_{1}$ is also called the dwell time of the F1 dimension. This means that the experimental spectral width $S W(\mathrm{~F} 1)$ in the $\mathrm{F} 1$ dimension is reduced to $S W(\mathrm{~F} 1) /(1+k)$. As a result, four more conventions have to be defined; we call them $C_{k(1)}, C_{4 b(1)}, C_{3 b(1)}$, and $C_{5 b(1)}$.

(ii) We keep the increment $\Delta t_{1}$ of the experimental evolution period untouched, but we scale the apparent carrier frequencies of conventions $C_{z}, C_{4 a}, C_{3 a}$, and $C_{5 a}$ by $1+k$. As a result, four new conventions have to be defined; we call them $C_{k(2)}, C_{4 b(2)}, C_{3 b(2)}$, and $C_{5 b(2)}$.

Similarly to Eqs. (7)-(10), the observed chemical shift of the center of gravity of the peak in the $\mathrm{F} 1$ dimension is defined for conventions $C_{k(1)}$ and $C_{k(2)}$ by

$$
\delta_{G 1-k}^{\mathrm{obs}}=\frac{\omega_{\mathrm{F} 1}(I, p)}{(1+k) \omega_{\mathrm{cf}}}=\frac{\delta_{G 1-z}^{\mathrm{obs}}}{1+k} ;
$$


for conventions $C_{4 b(1)}$ and $C_{4 b(2)}$ by

$$
\delta_{G 1-4 b}^{\mathrm{obs}}=\frac{\omega_{\mathrm{F} 1}(I, p)}{(1+k) p \omega_{\mathrm{cf}}}=\frac{\delta_{G 1-4 a}^{\mathrm{obs}}}{1+k} ;
$$

for conventions $C_{3 b(1)}$ and $C_{3 b(2)}$ by

$$
\delta_{G 1-3 b}^{\mathrm{obs}}=\frac{\omega_{\mathrm{F} 1}(I, p)}{(1+k)(k-p) \omega_{\mathrm{cf}}}=\frac{\delta_{G 1-3 a}^{\mathrm{obs}}}{1+k}
$$

and for conventions $C_{5 b(1)}$ and $C_{5 b(2)}$ by

$$
\delta_{G 1-5 b}^{\mathrm{obs}}=\frac{\omega_{\mathrm{F} 1}(I, p)}{(1+k)(k+\lambda) \omega_{\mathrm{cf}}}=\frac{\delta_{G 1-5 a}^{\mathrm{obs}}}{1+k} .
$$

The two parameters we modify are the increment of the experimental evolution period and the apparent carrier frequency in the F1 dimension. In fact, we will see later that a third parameter should be modified according to the convention. In the following we gather the various conventions into four groups and deduce the analytical expression of the observed chemical shift of the center of gravity of a peak in the $\mathrm{F} 1$ axis as a function of the isotropic chemical shift $\delta_{\mathrm{CS}}^{\text {iso }}$ and the second-order quadrupole shift $\omega_{-1 / 2,1 / 2}^{(2) \text {. }}$.

Conventions $C_{z}, C_{k(1)}$, and $C_{k(2)}$. In convention $C_{z}$, which is used by Medek and co-workers [96], all the experimental parameters remain untouched. The carrier frequency $\omega_{\text {cf }}$ in the F1 dimension is identical to that of the F2 dimension. As a result, the observed chemical shift of the center of gravity of the peak in the F1 dimension or Eq. (7) is

$$
\delta_{G 1-z}^{\mathrm{obs}}=(k-p) \delta_{\mathrm{CS}}^{\mathrm{iso}}+(k+\lambda) \frac{\omega_{-1 / 2,1 / 2}^{(2) \text { iso }}}{\omega_{\mathrm{cf}}}=k_{1 z} \delta_{\mathrm{CS}}^{\text {iso }}+k_{2 z} \frac{\omega_{-1 / 2,1 / 2}^{(2) \text { iso }}}{\omega_{\mathrm{cf}}} .
$$

The apparent carrier frequency in the F1 dimension and the increment of the evolution period are $\omega_{\mathrm{cf}}$ and $(1+k) \Delta t_{1}$ for convention $C_{k(1)}$, and $(1+k) \omega_{\mathrm{cf}}$ and $\Delta t_{1}$ for convention $C_{k(2)}$. These choices were introduced by Massiot and co-workers [97] because they use the evolution period $(1+k) t_{1}$ instead of the experimental evolution period. For these two conventions, the observed chemical shift of the center of gravity of the peak in the F1 dimension or Eq. (11) is

$$
\delta_{G 1-k}^{\mathrm{obs}}=\frac{1}{1+k}\left((k-p) \delta_{\mathrm{CS}}^{\mathrm{iso}}+(k+\lambda) \frac{\omega_{-1 / 2,1 / 2}^{(2) \text { iso }}}{\omega_{\mathrm{cf}}}\right)=k_{1 k} \delta_{\mathrm{CS}}^{\mathrm{iso}}+k_{2 k} \frac{\omega_{-1 / 2,1 / 2}^{(2) \text { iso }}}{\omega_{\mathrm{cf}}} .
$$

The four parameters $k_{1 z}, k_{2 z}, k_{1 k}$, and $k_{2 k}$ are given in Table 1 for the four halfinteger quadrupole spins.

Conventions $C_{4 a}, C_{4 b(1)}$, and $C_{4 b(2)}$. In convention $C_{4 a}$, the apparent carrier frequency in the F1 dimension is $p \omega_{\mathrm{cf}}$ and the increment of the evolution period remains $\Delta t_{1}$. These conditions were introduced by Bodart and co-workers [50], who 
extend the convention used for unsheared 2D MQ-MAS spectra to sheared spectra. The observed chemical shift of the center of gravity of the peak in the F1 dimension or Eq. (8) is

$$
\delta_{G 1-4 a}^{\mathrm{obs}}=\frac{k-p}{p} \delta_{\mathrm{CS}}^{\mathrm{iso}}+\frac{k+\lambda}{p} \frac{\omega_{-1 / 2,1 / 2}^{(2) \text { iso }}}{\omega_{\mathrm{cf}}}=k_{14} \delta_{\mathrm{CS}}^{\mathrm{iso}}+k_{24} \frac{\omega_{-1 / 2,1 / 2}^{(2) \text { iso }}}{\omega_{\mathrm{cf}}} .
$$

The apparent carrier frequency in the F1 dimension and the increment of the evolution period are $p \omega_{\mathrm{cf}}$ and $(1+k) \Delta t_{1}$ for convention $C_{4 b(1)}$, and $(1+k) p \omega_{\mathrm{cf}}$ and $\Delta t_{1}$ for convention $C_{4 \mathrm{~b}(2)}$. For these two conventions, the observed chemical shift of the center of gravity of the peak in the F1 dimension or Eq. (12) is

$$
\delta_{G 1-4 b}^{\mathrm{obs}}=\frac{1}{1+k}\left(k_{14} \delta_{\mathrm{CS}}^{\mathrm{iso}}+k_{24} \frac{\omega_{-1 / 2,1 / 2}^{(2) \text { iso }}}{\omega_{\mathrm{cf}}}\right) .
$$

The two parameters $k_{14}$ and $k_{24}$ are given in Table 1 for the four half-integer quadrupole spins.

Conventions $C_{3 a}, C_{3 b(1)}$, and $C_{3 b(2)}$. Convention $C_{3 a}$ was introduced by Amoureux and co-workers [23, 24], who consider $(k-p) \omega_{\mathrm{cf}}$ as the apparent carrier frequency of the F1 dimension and the increment of the experimental evolution period $\Delta t_{1}$. The observed chemical shift of the center of gravity of the peak in the F1 dimension or Eq. (9) is

$$
\delta_{G 1-3 a}^{\mathrm{obs}}=\delta_{\mathrm{CS}}^{\mathrm{iso}}+\frac{k+\lambda}{k-p} \frac{\omega_{-1 / 2,1 / 2}^{(2) \text { iso }}}{\omega_{\mathrm{cf}}}=\delta_{\mathrm{CS}}^{\text {iso }}-\frac{10}{17} \frac{\omega_{-1 / 2,1 / 2}^{(2) \text { iso }}}{\omega_{\mathrm{cf}}} .
$$

Contrary to the above conventions, the terms associated with $\delta_{\mathrm{CS}}^{\text {iso }}$ and $\omega_{-1 / 2,1 / 2}^{(2) \text { iso }} / \omega_{\mathrm{cf}}$ are constants, therefore, independent of the spin $I$ and the coherence order $p$.

The apparent carrier frequency in the $\mathrm{F} 1$ dimension and the increment of the evolution period are $(k-p) \omega_{\mathrm{cf}}$ and $(1+k) \Delta t_{1}$ for convention $C_{3 b(1)}$, and $(1+$ $k)(k-p) \omega_{\text {cf }}$ and $\Delta t_{1}$ for convention $C_{3 b(2)}$. For these two conventions, the observed chemical shift of the center of gravity of the peak in the F1 dimension or Eq. (13) is

$$
\delta_{G 1-3 b}^{\mathrm{obs}}=\frac{1}{1+k}\left(\delta_{\mathrm{CS}}^{\mathrm{iso}}-\frac{10}{17} \frac{\omega_{-1 / 2,1 / 2}^{(2) \text { iso }}}{\omega_{\mathrm{cf}}}\right) .
$$

The terms associated with $\delta_{\mathrm{CS}}^{\text {iso }}$ and $\omega_{-1 / 2,1 / 2}^{(2) \text { iso }} / \omega_{\mathrm{cf}}$ depend only on the position $k$ of the echo.

Conventions $C_{5 a}, C_{5 b(1)}$, and $C_{5 b(2)}$. We propose convention $C_{5 a}$ that considers $(k+\lambda) \omega_{\mathrm{cf}}$ as the apparent carrier frequency of the F1 dimension and the increment of the experimental evolution period $\Delta t_{1}$. The observed chemical shift of the center of gravity of the peak in the F1 dimension or Eq. (10) is

$$
\delta_{G 1-5 a}^{\mathrm{obs}}=\frac{k-p}{k+\lambda} \delta_{\mathrm{CS}}^{\mathrm{iso}}+\frac{\omega_{-1 / 2,1 / 2}^{(2) \text { iso }}}{\omega_{\mathrm{cf}}}=-\frac{17}{10} \delta_{\mathrm{CS}}^{\text {iso }}+\frac{\omega_{-1 / 2,1 / 2}^{(2) \text { iso }}}{\omega_{\mathrm{cf}}} .
$$


Similarly to Eq. (19), the terms associated with $\delta_{\mathrm{CS}}^{\text {iso }}$ and $\omega_{-1 / 2,1 / 2}^{(2) \text { iso }} / \omega_{\text {cf }}$ are also constants in Eq. (21).

The apparent carrier frequency in the F1 dimension and the increment of the evolution period are $(k+\lambda) \omega_{\mathrm{cf}}$ and $(1+k) \Delta t_{1}$ for convention $C_{5 b(1)}$, and $(1+$ $k)(k+\lambda) \omega_{\mathrm{cf}}$ and $\Delta t_{1}$ for convention $C_{5 b(2)}$. For these two conventions, the observed chemical shift of the center of gravity of the peak in the F1 dimension or Eq. (14) is

$$
\delta_{G 1-5 b}^{\mathrm{obs}}=\frac{1}{1+k}\left(-\frac{17}{10} \delta_{\mathrm{CS}}^{\text {iso }}+\frac{\omega_{-1 / 2,1 / 2}^{(2) \text { iso }}}{\omega_{\mathrm{cf}}}\right) .
$$

The terms associated with $\delta_{\mathrm{CS}}^{\text {iso }}$ and $\omega_{-1 / 2,1 / 2}^{(2) \text { iso }} / \omega_{\mathrm{cf}}$ depend only on the position $k$ of the echo.

In a theoretical study, the observed chemical shifts of the center of gravity of a peak in a 2D spectrum are referenced to the apparent carrier frequency in the F1 dimension and to the carrier frequency in the F2 dimension, which are located at the center of each of the two spectral widths. Of course, the off-resonance positions $\Delta \omega_{\mathrm{F} 1}$ and $\Delta \omega_{\mathrm{F} 2}$ of a peak are always referenced to the apparent carrier frequency and to the carrier frequency. From a practical point of view, in a 1D spectrum or the F2 dimension of a 2D spectrum, the chemical shift of an absorption line is referenced experimentally to an external aqueous solution with $\delta_{\mathrm{CS}}^{\text {iso }}=0$, by definition. Knowing $\Omega_{\mathrm{F} 1}$, the frequency offset of the apparent carrier frequency relative to the aqueous solution in the F1 dimension, and $\Omega_{\mathrm{F} 2}$, that of the carrier frequency relative to the aqueous solution in the F2 dimension, we can express the observed chemical shifts of the center of gravity, $\delta_{G 1}^{\mathrm{obs}}$ in the F1 dimension and $\delta_{G 2}^{\mathrm{obs}}$ in the $\mathrm{F} 2$ dimension, of any peak relative to the aqueous solution. Unfortunately, $\Delta \omega_{\mathrm{F} 1}$ and $\Omega_{\mathrm{F} 1}$ differ from $\Delta \omega_{\mathrm{F} 2}$ and $\Omega_{\mathrm{F} 2}$ for a $2 \mathrm{D}$ MQ-MAS spectrum. Since the Hamiltonian associated with a frequency offset and that with the isotropic chemical shift are similar, the expressions for the isotropic chemical shift (see Tables 2-4) remain valid for the frequency offset and the off-resonance position.

For conventions $C_{z}, C_{3 a}, C_{4 a}, C_{5 a}, C_{k(2)}, C_{3 b(2)}, C_{4 b(2)}$, and $C_{5 b(2)}$ where the increment of the experimental evolution period remains unchanged, the frequency offset of the apparent carrier frequency relative to the aqueous solution and the offresonance position of the peak relative to the apparent carrier frequency in the F1 dimension are

$$
\begin{gathered}
\Omega_{\mathrm{F} 1}=(k-p) \Omega_{\mathrm{F} 2}=k_{1 z} \Omega_{\mathrm{F} 2}, \\
\Delta \omega_{\mathrm{F} 1}=(k-p) \Delta \omega_{\mathrm{F} 2}=k_{1 z} \Delta \omega_{F 2} .
\end{gathered}
$$

On the other hand, for conventions $C_{k(1)}, C_{3 b(1)}, C_{4 b(1)}$, and $C_{5 b(1)}$ where the increment of the experimental evolution period is multiplied by $1+k$, the frequency offset and the off-resonance position in the F1 dimension are

$$
\begin{aligned}
\Omega_{\mathrm{F} 1} & =\frac{k-p}{1+k} \Omega_{\mathrm{F} 2}=k_{1 k} \Omega_{\mathrm{F} 2}, \\
\Delta \omega_{\mathrm{F} 1} & =\frac{k-p}{1+k} \Delta \omega_{\mathrm{F} 2}=k_{1 k} \Delta \omega_{\mathrm{F} 2} .
\end{aligned}
$$




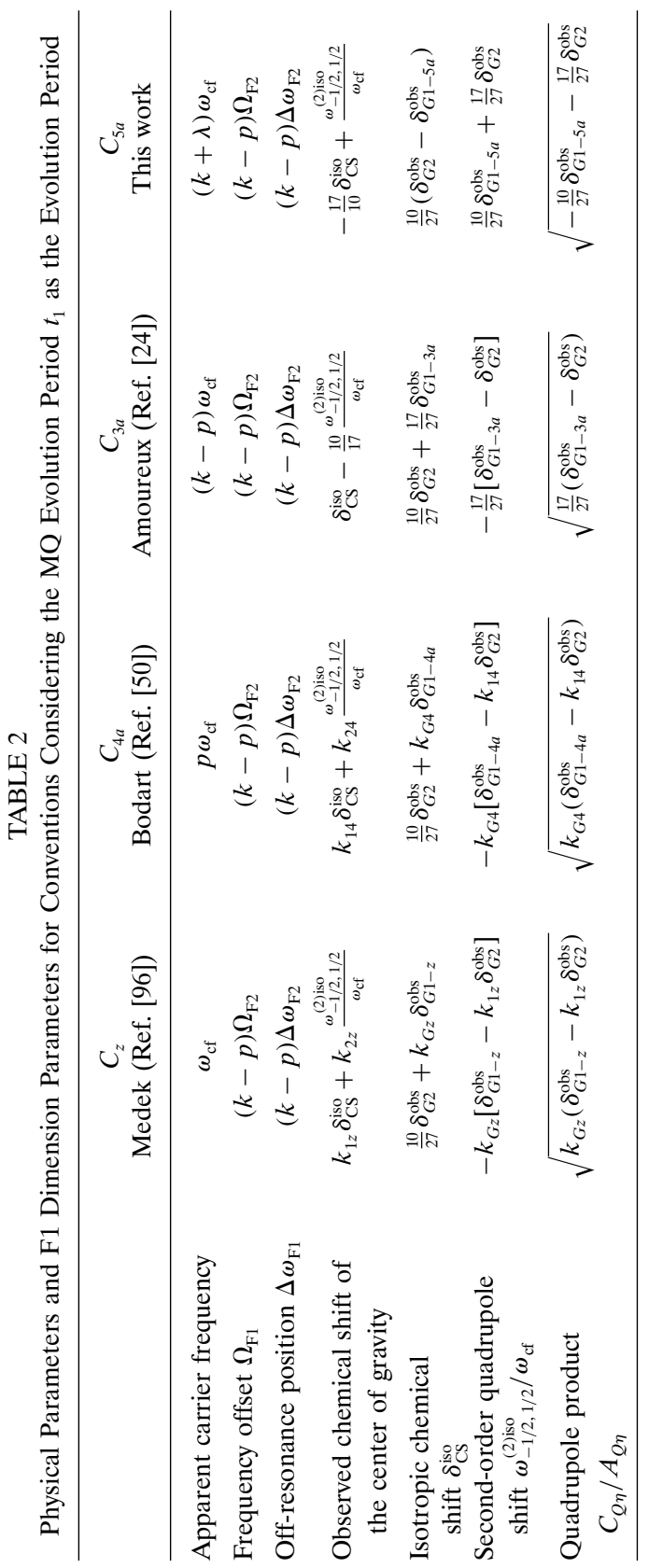




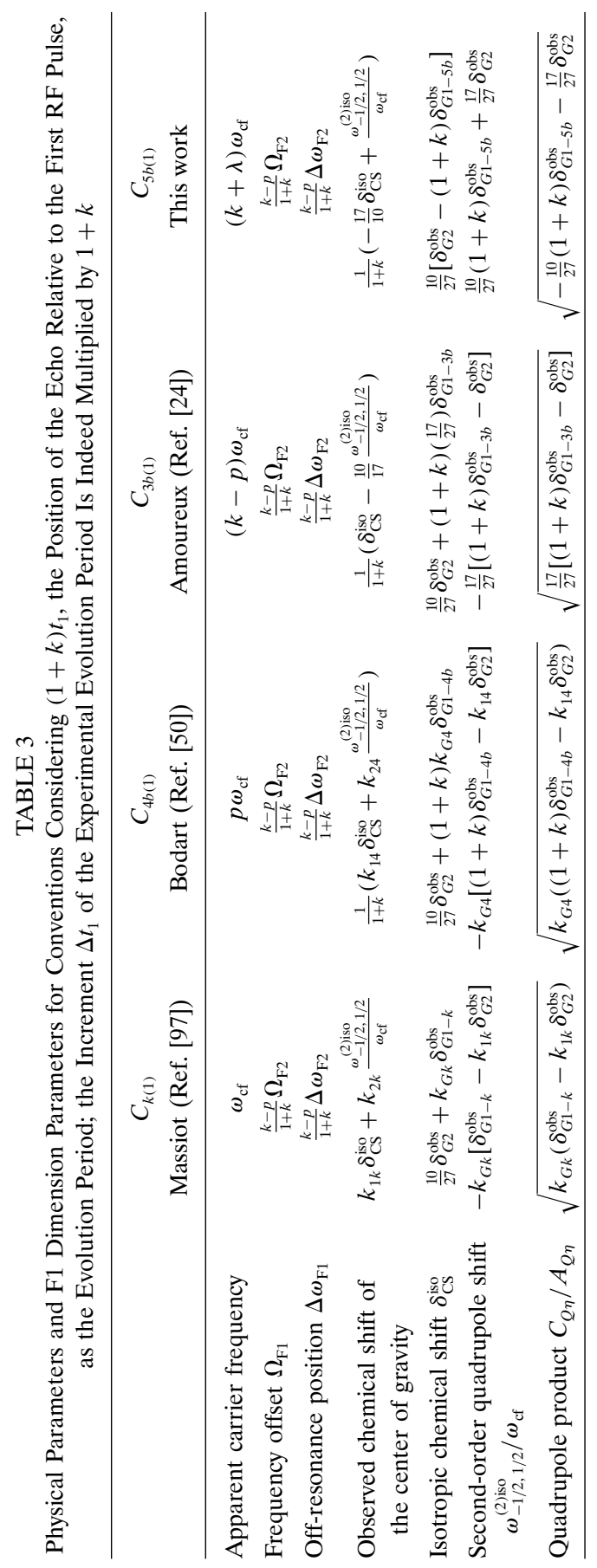




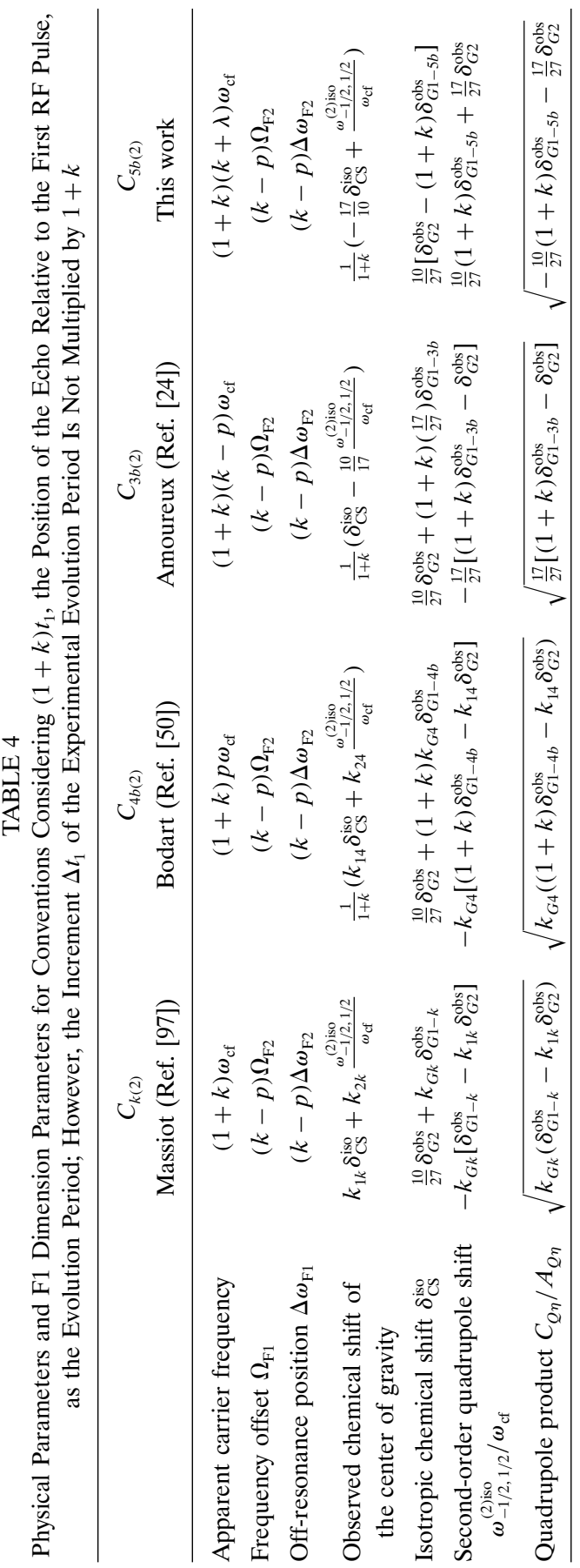


Now we know (i) $\Delta \omega_{\mathrm{F} 1}$, the off-resonance position of a peak relative to the apparent carrier frequency in the F1 dimension; (ii) $\Delta \omega_{\mathrm{F} 2}$, that relative to the carrier frequency in the F2 dimension; (iii) $\Omega_{\mathrm{F} 1}$, the frequency offset of the apparent carrier frequency relative to the aqueous solution in the F1 dimension; and (iv) $\Omega_{\mathrm{F} 2}$, that of the carrier frequency relative to the same solution in the F2 dimension. Therefore we know the positions of the peak relative to the aqueous solution in both dimensions.

Once the two axes of the 2D MQ-MAS spectrum are labeled in chemical shift units, with one of the above conventions for the F1 dimension and the usual convention for the F2 dimension, we would like to determine the isotropic chemical shift $\delta_{\mathrm{CS}}^{\text {iso }}$ and the quadrupole product $C_{Q \eta}$ associated with a peak. The observed chemical shift $\delta_{G 2}^{\text {obs }}$ of the center of gravity of a peak in the F2 dimension is

$$
\delta_{G 2}^{\mathrm{obs}}=\delta_{\mathrm{CS}}^{\mathrm{iso}}+\frac{\omega_{-1 / 2,1 / 2}^{(2) \text { iso }}}{\omega_{\mathrm{cf}}} .
$$

Combining Eq. (27) successively with Eqs. (15)-(22) provides us with the expressions of the isotropic chemical shift $\delta_{\mathrm{CS}}^{\text {iso }}$, the second-order quadrupole shift $\omega_{-1 / 2,1 / 2}^{(2) \text { iso }} / \omega_{\text {cf }}$ expressed in chemical shift units, and the quadrupole product $C_{Q \eta}$ for each convention. They are gathered in Tables $2-4$. The key points for conventions $C_{3 a}$ and $C_{5 a}$ are that the expressions of $\delta_{\mathrm{CS}}^{\text {iso }}$ and $\omega_{-1 / 2,1 / 2}^{(2) \text { iso }} / \omega_{\mathrm{cf}}$ are independent of the spin $I$, the coherence order $p$, the position $k$ of the echo, and $\lambda$. For convention $C_{3 a}$,

$$
\delta_{\mathrm{CS}}^{\mathrm{iso}}=\frac{10}{27} \delta_{G 2}^{\mathrm{obs}}+\frac{17}{27} \delta_{G 1-3 a}^{\mathrm{obs}}, \quad \frac{\omega_{-1 / 2,1 / 2}^{(2) \text { iso }}}{\omega_{\mathrm{cf}}}=-\frac{17}{27}\left[\delta_{G 1-3 a}^{\mathrm{obs}}-\delta_{G 2}^{\mathrm{obs}}\right] .
$$

For convention $C_{5 a}$,

$$
\delta_{\mathrm{CS}}^{\mathrm{iso}}=\frac{10}{27}\left(\delta_{G 2}^{\mathrm{obs}}-\delta_{G 1-5 a}^{\mathrm{obs}}\right), \quad \frac{\omega_{-1 / 2,1 / 2}^{(2) \text { iso }}}{\omega_{\mathrm{cf}}}=\frac{10}{27} \delta_{G 1-5 a}^{\mathrm{obs}}+\frac{17}{27} \delta_{G 2}^{\mathrm{obs}} .
$$

In addition to the apparent carrier frequency and the increment of the evolution period, we have to use $\Omega_{\mathrm{F} 1}$. For the convenience of readers, we have gathered these parameters and the physical parameters in Tables $2-4$ for the various conventions. The first rows concerning the apparent carrier frequencies in Tables 2 and 3 are identical. Similarly, the second and third rows concerning the frequency offsets and the off-resonance positions in Tables 2 and 4 are identical. On the other hand, Tables 3 and 4 differ only in the first three rows; the other rows of these two tables are identical.

Of all these conventions, only $C_{z}$ and $C_{k(1)}$ have the same carrier frequency $\omega_{\mathrm{cf}}$ for the two dimensions of a 2D MQ-MAS spectrum. For these two conventions and $C_{k(2)}$, the apparent carrier frequency is always positive. This is not the case for the remaining conventions whose apparent carrier frequencies change sign depending on the spin $I$ and the coherence order $p$. Since most NMR processing programs do not accept negative carrier frequencies, if the apparent carrier frequency is indeed negative, we have to change its sign, reverse the $\mathrm{F} 1$ axis, and change the sign of $\Omega_{\mathrm{F} 1}$ as well. Otherwise, we have to use conventions whose apparent carrier frequencies 
are always positive. This is the reason for which conventions $C_{z}[38,59,96,98,106-$ $108]$ and $C_{k(1)}[17,29,68,72,77,87,91,93,97,98,109-111]$ are the most applied.

However, convention $C_{3 a}[42,48,49,53,55,64,65,70]$ is also often applied, despite the fact that for a 3Q-MAS experiment, only spin $I=3 / 2$ nuclei have positive apparent carrier frequencies; spin $I=5 / 2,7 / 2$, or $9 / 2$ nuclei have negative ones. This is due to the fact that the two physical parameters $\delta_{\mathrm{CS}}^{\text {iso }}$ and $\omega_{-1 / 2,1 / 2}^{(2) \text { iso }} / \omega_{\mathrm{cf}}$ (see Eq. (28)) are independent of the spin $I$ and the coherence order $p$. This is not the case for conventions $C_{z}$ and $C_{k(1)}$. The apparent carrier frequencies $(k-p) \omega_{\mathrm{cf}}$ of convention $C_{3 a}$ and $(k+\lambda) \omega_{\mathrm{cf}}$ of convention $C_{5 a}$ have opposite signs. Convention $C_{5 a}$ presents fewer negative carrier frequencies than convention $C_{3 a}$, four instead of six. They correspond to coherence order $p=-I$. Furthermore, the two physical parameters $\delta_{\mathrm{CS}}^{\text {iso }}$ and $\omega_{-1 / 2,1 / 2}^{(2)} / \omega_{\text {cf }}$ (see Eq. (29)) are also independent of the spin $I$ and the coherence order $p$. In other words, conventions $C_{3 a}$ and $C_{5 a}$ are similar.

\section{EXPERIMENTAL}

The ${ }^{27} \mathrm{Al}$ and ${ }^{23} \mathrm{Na} 2 \mathrm{D}$ 3Q-MAS spectra were obtained on Bruker spectrometers ASX-500 operating at $130.31 \mathrm{MHz}$ and ASX-300 operating at $79.39 \mathrm{MHz}$, respectively. Standard high-power MAS probeheads equipped with 4-mm diameter rotors were used. The rotor spinning $\nu_{\text {rot }}$ rate was $10 \mathrm{kHz}$. The acquisition of the two $t_{2}$-domain signals in quadrature was performed in the simultaneous mode. The two-pulse 3Q-MAS acquisition program followed the hypercomplex procedure [105, 112]. Therefore, the simultaneous acquisition mode was applied in both dimensions. The chemical shift was referenced to external aqueous solutions of 1-M $\mathrm{Al}\left(\mathrm{NO}_{3}\right)_{3}$ and $1-\mathrm{M} \mathrm{NaCl}$. Other experimental conditions such as the number of scans $N S$, the recycle delay $D 1$, the first- and second-pulse durations $P 1$ and $P 2$, the spectral width in the F2 dimension $S W(\mathrm{~F} 2)$, the frequency offset $\Omega_{F 2}$ of the carrier frequency relative to the aqueous solution in the F2 dimension, and the spectral width in the F1 dimension $S W(\mathrm{~F} 1)$ are given in the figure caption. Data processing, including the shearing transformation, was performed with the RMN(FAT) program written by Grandinetti [113].

\section{RESULTS}

Figure 2 shows an expansion of the sheared 2D 3Q-MAS spectrum of ${ }^{27} \mathrm{Al}$ in aluminum acetylacetonate. The F1 axis is labeled with the several conventions discussed in this paper. Table 5 presents the numerical values of the three experimental parameters that have to be modified according to the convention used: the increment $\Delta t_{1}=50 \mu \mathrm{s}$ of the experimental evolution period or the dwell time in the F1 dimension, the apparent carrier frequency, and the frequency offset $\Omega_{\mathrm{F} 1}$ of the apparent carrier frequency relative to the aqueous solution in the F1 dimension. The $\mathrm{F} 1$ axes for conventions $C_{3 a}, C_{3 b(1)}$, and $C_{3 b(2)}$ used by Amoureux and Fernandez $[23,24]$ are oriented in the opposite direction to those of the other conventions. The observed chemical shift of the center of gravity of the peak in the F1 axis depends of course on the conventions: $\delta_{G 1-z}^{\mathrm{obs}}=-2.54 \mathrm{ppm}$ for $C_{z}, \delta_{G 1-k}^{\mathrm{obs}}=-0.98 \mathrm{ppm}$ for $C_{k(1)}$ and $C_{k(2)}, \delta_{G 1-3 a}^{\text {obs }}=1.79 \mathrm{ppm}$ for $C_{3 a}, \delta_{G 1-3 b}^{\text {obs }}=0.69 \mathrm{ppm}$ for $C_{3 b(1)}$ and 


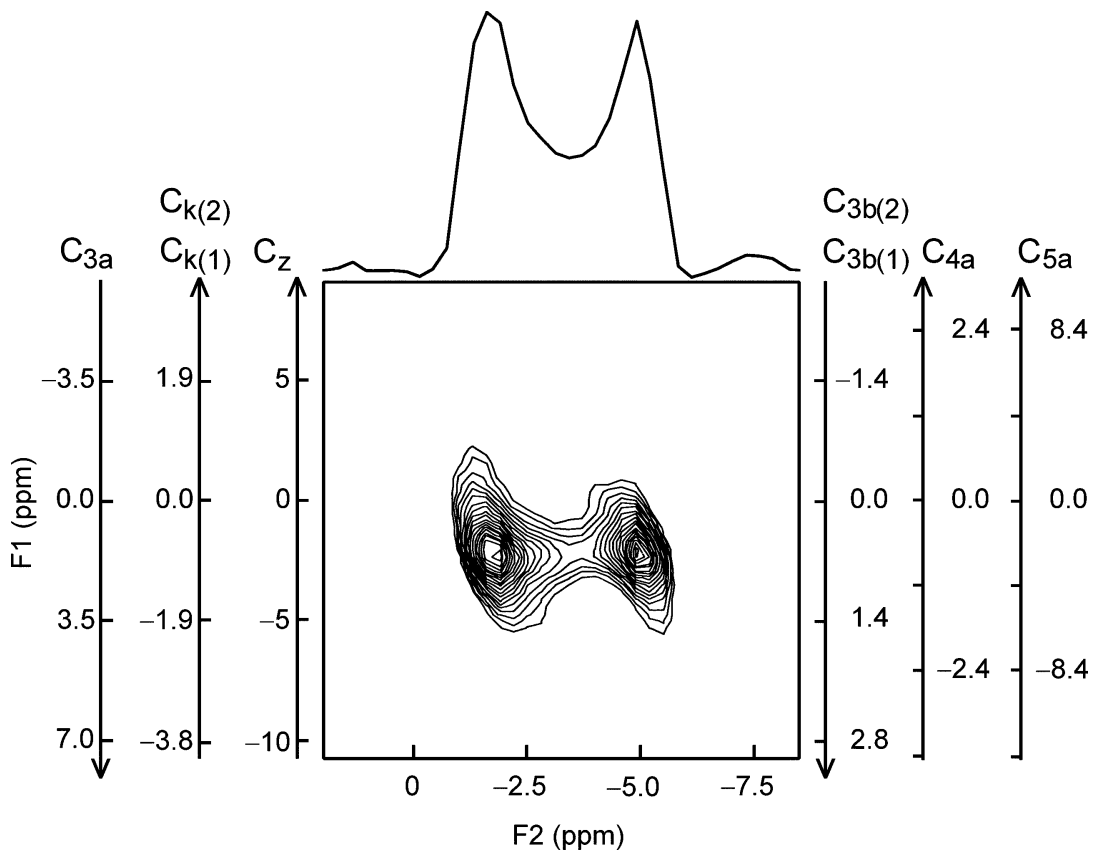

FIG. 2. Zoomed contour-plot of the sheared 2D 3Q-MAS spectrum of the ${ }^{27} \mathrm{Al}\left(I=\frac{5}{2}\right)$ nuclei in aluminum acetylacetonate, recorded at $130.3 \mathrm{MHz}$ (ASX500). The axis of the F1 dimension is labeled with several conventions discussed in this paper. $N S=24, D 1=3 \mathrm{~s}, \nu_{\text {rot }}=10 \mathrm{kHz}, P 1=3.5 \mu \mathrm{s}$, $P 2=0.75 \mu \mathrm{s}, T D(\mathrm{~F} 2)=1024$ points, $S W(\mathrm{~F} 2)=20 \mathrm{kHz}, \Omega_{\mathrm{F} 2}=-445 \mathrm{~Hz}, T D(\mathrm{~F} 1)=256$ points, and $S W(\mathrm{~F} 1)=20 \mathrm{kHz}$.

$C_{3 b(2)}, \delta_{G 1-4 a}^{\mathrm{obs}}=-0.84 \mathrm{ppm}$ for $C_{4 a}$, and $\delta_{G 1-5 a}^{\mathrm{obs}}=-3.04 \mathrm{ppm}$ for $C_{5 a}$. For the F2 dimension, the observed chemical shift of the center of gravity of the peak is $\delta_{G 2}^{\text {obs }}=-3.16 \mathrm{ppm}$. On the other hand, the quadrupole coupling constant, deduced from $\delta_{G 1}^{\text {obs }}$ and $\delta_{G 2}^{\text {obs }}$ using the various formulas in Tables 2-4, is independent of the convention: $C_{Q}=2.97 \mathrm{MHz}$, assuming $\eta=0$. That found by Ding and McDowell [114] is $C_{Q}=3.0 \mathrm{MHz}$ with $\eta=0.0$. Those of Barrie [115] and of Ashbrook and co-workers [16] are $C_{Q}=3.0 \mathrm{MHz}$ with $\eta=0.15$.

Now we deal with the second topic of the paper, the aliasing of $2 \mathrm{D}$ peaks which are not on-resonance in the F2 dimension due to the effect of the chemical shift. This should occur when the sample presents several crystallographic sites for the nuclei with a large chemical-shift range. Therefore, some peaks in the F2 dimension should be off-resonance. We simulate the effect of the chemical shift on a single peak by changing its off-resonance position in the F2 dimension, that is, by changing the carrier frequency in the F2 dimension. If peak aliasing in the F2 dimension is easy to deal with experimentally by changing the value of $S W(\mathrm{~F} 2)$ in the $1 \mathrm{D}$ experiment, it is not the case for the F1 dimension. It depends on the value of $S W(\mathrm{~F} 1)$. There are two approaches to solve this problem: (1) We can keep fixed the off-resonance position of the peak in the F2 dimension and $S W(\mathrm{~F} 2)$, but change $S W(\mathrm{~F} 1)$ to see when the aliasing occurs in the F1 dimension. (2) We can keep fixed 
TABLE 5

Parameters Involved in Labeling the F1 Dimension of ${ }^{27} \mathrm{Al}$ 3Q-MAS Spectrum of Aluminum Acetylacetonate (Fig. 2), According to the Various Conventions

\begin{tabular}{lrrr}
\hline Convention & $\begin{array}{c}\text { Dwell time } \\
(\mu \mathrm{s})\end{array}$ & $\begin{array}{c}\text { Apparent carrier frequency } \\
(\mathrm{MHz})\end{array}$ & $\begin{array}{c}\text { Frequency offset } \Omega_{\mathrm{F} 1} \\
(\mathrm{~Hz})\end{array}$ \\
\hline$C_{z}$ & $\Delta t_{1}=50$ & $\omega_{\mathrm{cf}} /(2 \pi)=130.315$ & $(k-p) \Omega_{\mathrm{F} 2}=631$ \\
$C_{k(1)}$ & $\omega_{\mathrm{cf}} /(2 \pi)=130.315$ & $\left(\frac{k-p}{1+k}\right) \Omega_{\mathrm{F} 2}=244$ \\
$C_{k(2)}$ & $\Delta t_{1}=50$ & $(1+k) \omega_{\mathrm{cf}} /(2 \pi)=336.647$ & $(k-p) \Omega_{\mathrm{F} 2}=631$ \\
$C_{3 a}$ & $\Delta t_{1}=50$ & $(k-p) \omega_{\mathrm{cf}} /(2 \pi)=-184.612^{a}$ & $(k-p) \Omega_{\mathrm{F} 2}=631^{a}$ \\
$C_{3 b(1)}$ & $(1+k) \Delta t_{1}=129$ & $(k-p) \omega_{\mathrm{cf}} /(2 \pi)=-184.612^{a}$ & $\left(\frac{k-p}{1+k}\right) \Omega_{\mathrm{F} 2}=244^{a}$ \\
$C_{3 b(2)}$ & $\Delta t_{1}=50$ & $p \omega_{\mathrm{cf}} /(2 \pi)=390.945$ & $(k-p) \Omega_{\mathrm{F} 2}=631^{a}$ \\
$C_{4 a}$ & $\Delta t_{1}=50$ & $p \omega_{\mathrm{cf}} /(2 \pi)=390.945$ & $(k-p) \Omega_{\mathrm{F} 2}=631$ \\
$C_{4 b(1)}$ & $(1+k) \Delta t_{1}=129$ & $(1+k) p \omega_{\mathrm{cf}} /(2 \pi)=1009.941$ & $(k-p) \Omega_{\mathrm{F} 2}=631$ \\
$C_{4 b(2)}$ & $\Delta t_{1}=50$ & $(k+\lambda) \omega_{\mathrm{cf}} /(2 \pi)=108.595$ & $(k-p) \Omega_{\mathrm{F} 2}=631$ \\
$C_{5 a}$ & $\Delta t_{1}=50$ & $(k+\lambda) \omega_{\mathrm{cf}} /(2 \pi)=108.595$ & $\left(\frac{k-p}{1+k}\right) \Omega_{\mathrm{F} 2}=244$ \\
$C_{5 b(1)}$ & $(1+k) \Delta t_{1}=129$ & $(1+k)(k+\lambda) \omega_{\mathrm{cf}} /(2 \pi)=280.539$ & $(k-p) \Omega_{\mathrm{F} 2}=631$ \\
$C_{5 b(2)}$ & $\Delta t_{1}=50$ & & $=64$ \\
\hline
\end{tabular}

Note. The frequency offset of the carrier frequency relative to the aqueous solution in the F2 dimension is $\Omega_{\mathrm{F} 2}=-445 \mathrm{~Hz}$. For a spin $I=5 / 2$ and $p=3, k=19 / 12, k-p=-17 / 12$, and $1+k=31 / 12$.

${ }^{a}$ If NMR software rejects negative spectrometer frequencies, we have to introduce a positive apparent carrier frequency for the $\mathrm{F} 1$ dimension. As a result, we have to reverse the F1 axis and change the sign of $\Omega_{\mathrm{F} 1}$.

$S W(\mathrm{~F} 1)$ and $S W(\mathrm{~F} 2)$, but change the off-resonance position of the peak in the $\mathrm{F} 2$ dimension. Since changing the $S W(\mathrm{~F} 1)$ value also changes the duration of the $2 \mathrm{D}$ experiment, we have chosen the second approach in order to keep most of the parameters unchanged.

Figure 3 shows the superposition of eight contour plots of sheared 2D 3Q-MAS spectra of ${ }^{27} \mathrm{Al}$ in $\mathrm{NH}_{4} \mathrm{Y}$ zeolite, each acquired with a different carrier frequency, which decreases from (1) to (8). Therefore, the frequency offset $\Omega_{\mathrm{F} 2}$ of the carrier frequency relative to the aqueous solution in the F2 dimension also decreases from (1) to (8). Conversely, the off-resonance position $\Delta \omega_{\mathrm{F} 2}$ of the peak relative to the carrier frequency increases from (1) to (8). The F1 axis is labeled with convention $C_{z}$. Increasing the off-resonance position $\Delta \omega_{\mathrm{F} 2}$ towards the high-frequency side of $S W(\mathrm{~F} 2)$ moves the aluminum peak from position 1 to position 4 , that is, towards the high-frequency side of $S W(\mathrm{~F} 2)$ and towards the low-frequency side of $S W(\mathrm{~F} 1)$; their observed chemical shifts of the center of gravity in the two dimensions are unchanged $\left(\delta_{G 1-z}^{\mathrm{obs}}, \delta_{G 2}^{\mathrm{obs}}\right)=(-89.12 \mathrm{ppm}, 61.20 \mathrm{ppm})$. A further increase in $\Delta \omega_{\mathrm{F} 2}$ moves the peak to position 5 with $\left(\delta_{G 1-z}^{\text {obs }}, \delta_{G 2}^{\text {obs }}\right)=(219.04 \mathrm{ppm}, 61.20 \mathrm{ppm})$. The peak is aliased [116] or "wrapped-around" $S W(\mathrm{~F} 1)$ to appear at the opposite end of $S W(\mathrm{~F} 1)$, because its observed chemical shift $\delta_{G 1-z}^{\text {obs }}$ differs from that of previous positions, an increase of $306 \mathrm{ppm}$ corresponding to $S W(\mathrm{~F} 1)$ expressed in chemical shift units. A further increase in $\Delta \omega_{2}$ divides the peak into two parts, one half being at position 6 and the other half at position 6'. Peak 6 is aliased twice in the F1 


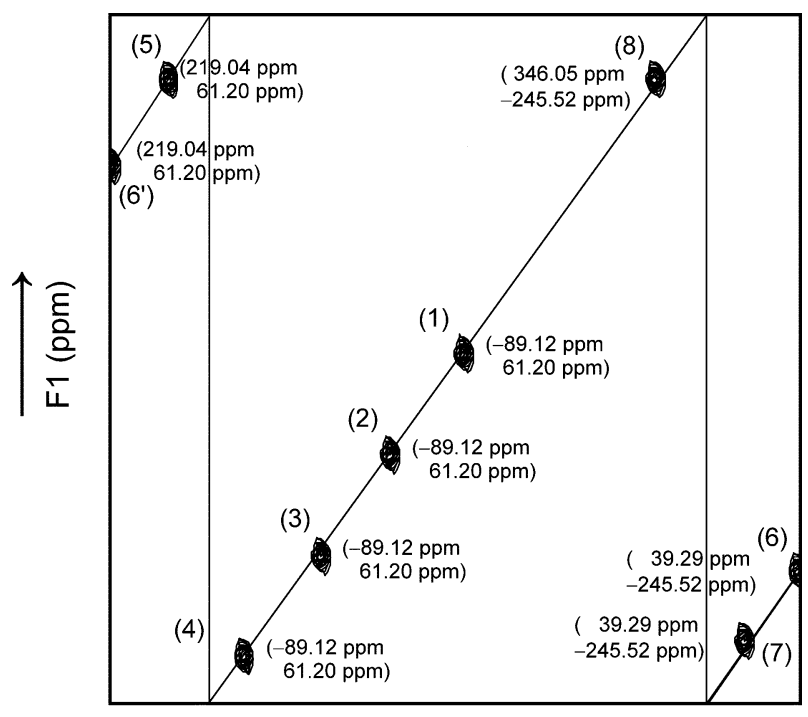

F2 (ppm)

FIG. 3. Effect of the frequency offset $\Omega_{\mathrm{F} 2}$ of the carrier frequency relative to the aqueous solution in the F2 dimension on the position of a peak. Superposition of eight contour plots of sheared 2D 3Q-MAS spectra of the ${ }^{27} \mathrm{Al}\left(I=\frac{5}{2}\right)$ nuclei in $\mathrm{NH}_{4} \mathrm{Y}$ zeolite, recorded at $130.3 \mathrm{MHz}$ (ASX500). The frequency offset $\Omega_{\mathrm{F} 2}$ decreases from (1) to (8). The axis of the F1 dimension is labeled with convention $C_{z}$. The values in parentheses give the position of the peak: the upper number is for the F1 axis and the lower one is for the F2 axis. $N S=120, D 1=300 \mathrm{~ms}, \nu_{\text {rot }}=10 \mathrm{kHz}, P 1=3 \mu \mathrm{s}, P 2=0.75 \mu \mathrm{s}, T D(\mathrm{~F} 2)=512$ points, $S W(\mathrm{~F} 2)=40 \mathrm{kHz}, T D(\mathrm{~F} 1)=256$ points, and $S W(\mathrm{~F} 1)=40 \mathrm{kHz}$.

dimension and once in the F2 dimension. It is worth noticing that positions 1 to 4 and 8 are aligned. The slope of this line is $(k-p)$, that of $\Delta \omega_{\mathrm{F} 1}=(k-p) \Delta \omega_{\mathrm{F} 2}$ for convention $C_{z}$ (see Table 2). In this example the slope $k-p=-17 / 12$ is negative; increasing the off-resonance position of the peak towards the high-frequency side of $S W(\mathrm{~F} 2)$ would cause aliasing of the peak around the high-frequency side of $S W(\mathrm{~F} 1)$. In other words, as long as $S W(\mathrm{~F} 1)$ is larger than $|k-p|$ times twice the offresonance position $\Delta \omega_{2}$ of a peak in the F2 dimension, a value easily obtained with a $1 \mathrm{D}$ experiment, the peak is not aliased in the $\mathrm{F} 1$ dimension of a $2 \mathrm{D}$ spectrum.

Figure 4 shows three contour plots of sodium nuclei in $\mathrm{Na}_{4} \mathrm{P}_{2} \mathrm{O}_{7}$. The $\mathrm{F} 2$ dimension has been reduced for clarity. Of the four sites for sodium nuclei, the peaks of sites 3 and 4 are resolved in the F1 dimension but not those of sites 1 and 2 at the carrier frequency $\omega_{\text {cf }} /(2 \pi)=79.4 \mathrm{MHz}$. All four peaks are resolved at higher carrier frequency [65-67]. Since the slope $k-p=34 / 9$ of the off-resonance position curve $\Delta \omega_{\mathrm{F} 1}=(k-p) \Delta \omega_{\mathrm{F} 2}$ is positive for $I=3 / 2, k=7 / 9$, and $p=-3$, and the ratio of spectral widths $S W(\mathrm{~F} 1) / S W(\mathrm{~F} 2)=33.33 / 20$ is not larger than $34 / 9$, aliasing of peaks should occur here. Increasing the off-resonance position $\Delta \omega_{\mathrm{F} 2}$ towards the high-frequency side of $S W(\mathrm{~F} 2)$ from Fig. 4a to Fig. $4 \mathrm{~b}$ shifts the peaks towards the high-frequency side of $S W(\mathrm{~F} 1)$. Further increase in $\Delta \omega_{\mathrm{F} 2}$ as in Fig. $4 \mathrm{c}$ aliases the 
(a)

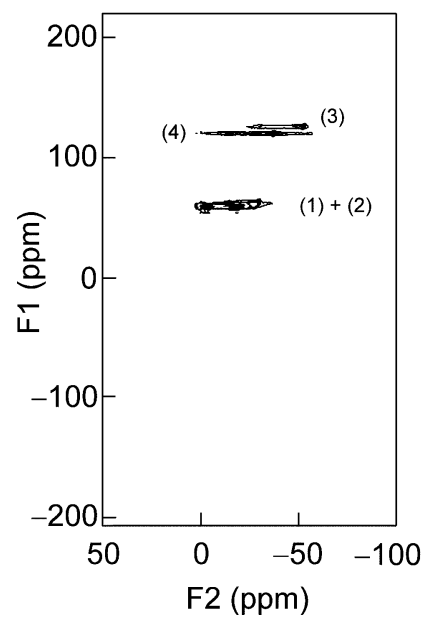

(b)

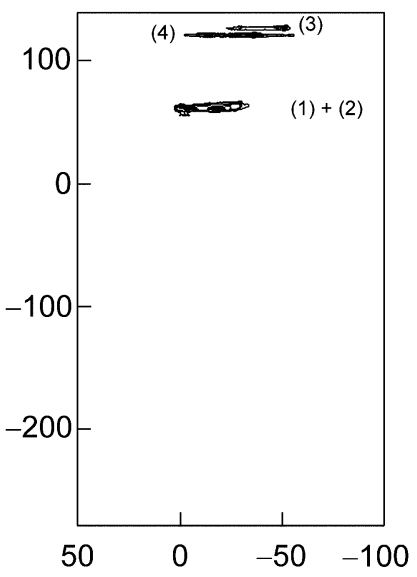

(c)

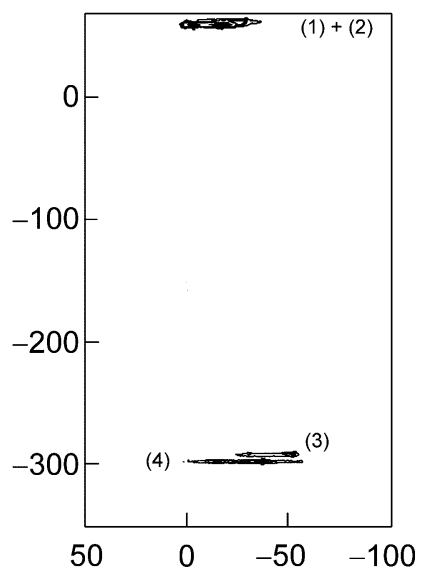

FIG. 4. Effect of the frequency offset $\Omega_{\mathrm{F} 2}$ of the carrier frequency relative to the aqueous solution in the F2 dimension on the position of a peak. Contour plots of the sheared 2D 3Q-MAS spectrum of the ${ }^{23} \mathrm{Na}\left(I=\frac{3}{2}\right)$ nuclei in sodium pyrophosphate, recorded at $79.4 \mathrm{MHz}$ (ASX300). The frequency offset $\Omega_{\mathrm{F} 2}$ of the carrier frequency relative to the aqueous solution in the F2 dimension decreases from (a) to (c). The axis of the F1 dimension is labeled with convention $C_{z} . N S=48, D 1=4 \mathrm{~s}, \nu_{\mathrm{rot}}=10 \mathrm{kHz}$, $P 1=9 \mu \mathrm{s}, P 2=9 \mu \mathrm{s}, T D(\mathrm{~F} 2)=1024$ points, $S W(\mathrm{~F} 2)=20 \mathrm{kHz}, T D(\mathrm{~F} 1)=200$ points, and $S W(\mathrm{~F} 1)=$ $33.33 \mathrm{kHz}$. The $\mathrm{F} 2$ dimension has been shortened.

peaks of sites 3 and 4 from the low-frequency side of $S W(\mathrm{~F} 1)$; fortunately, the peaks of sites 1 and 2 are not aliased. Thanks to the relation $\Delta \omega_{\mathrm{F} 1}=(k-p) \Delta \omega_{\mathrm{F} 2}$ in convention $C_{z}$, it is easy to recognize aliased peaks among nonaliased peaks in a 2D MQ-MAS spectrum In order to avoid peak aliasing, before the MQ-MAS experiment starts, we should choose $S W(F 1)$ so that the ratio $S W(F 1) / S W(F 2)$ is larger than $|k-p|$. From the observed chemical shifts of the center of gravity of the peaks of sites 3 and 4 in Fig. $4 \mathrm{a}$, the quadrupole products are $C_{Q_{\eta}}=3.44 \mathrm{MHz}$ for site 3 and $C_{Q \eta}=3.09 \mathrm{MHz}$ for site 4. Engelhardt and co-workers [65] found that $C_{Q \eta}=3.4$ MHz with $\eta=0.56$ for site 3 and $C_{Q \eta}=3.0 \mathrm{MHz}$ with $\eta=0.47$ for site 4 .

We have presented peak aliasing when the simultaneous mode of signal acquisition is applied in both dimensions. We did not discuss the second way that is also worth presenting, the sequential mode of signal acquisition that the TPPI method implements. It is recommended to apply the same acquisition mode in both dimensions in order to control peak aliasing, if the condition $S W(\mathrm{~F} 1) / S W(\mathrm{~F} 2)>|k-p|$ cannot be satisfied.

\section{CONCLUSION}

The acquisition condition for avoiding the aliasing of peaks and the various conventions for labeling the F1 axis of a sheared 2D MQ-MAS spectrum have been presented and analyzed. The three parameters to be modified are the increment of the experimental evolution period, the apparent carrier frequency in the F1 dimension, 
and the frequency offset of the apparent carrier frequency relative to the aqueous solution. The isotropic chemical shift $\delta_{\mathrm{CS}}^{\text {iso }}$ and the second-order quadrupole shift $\omega_{-1 / 2,1 / 2}^{(2) \text { iso }}$ of a peak can be deduced from the two observed chemical shifts of the center of gravity of the peak in the two dimensions F1 and F2, using appropriate formulas (see Tables 2-4). In fact three conventions dominate the literature: convention $C_{z}$ introduced by Medek and co-workers [96], convention $C_{k(1)}$ introduced by Massiot and co-workers [97], and convention $C_{3 a}$ introduced by Amoureux and Fernandez [23, 24]. The apparent carrier frequencies in the first two conventions are always positive. The price to pay is that there are many numerical factors (see Table 1) involved in the expressions of $\delta_{\mathrm{CS}}^{\text {iso }}$ and $\omega_{-1 / 2,1 / 2}^{(2) \text { iso }}$, depending on the spin $I$ and the coherence order $p$. On the other hand, convention $C_{3 a}$ presents one expression for $\delta_{\mathrm{CS}}^{\text {iso }}$ and another one for $\omega_{-1 / 2,1 / 2}^{(2) \text { iso }}$, independent of $I$ and $p$. The price to pay is that the apparent carrier frequency changes sign depending on $I$ and $p$, which requires additional data processing if the apparent carrier frequency is negative. We have proposed another convention called $C_{5 a}$, having the same properties as $C_{3 a}$. For a given $I$ and $p$, the signs of their carrier frequencies are different; otherwise, these two conventions are similar.

\section{REFERENCES}

1. L. Frydman and J. S. Harwood, Isotropic spectra of half-integer quadrupolar spins from bidimensional MAS NMR, J. Am. Chem. Soc. 117, 5367-5368 (1995).

2. A. Goldbourt, P. K. Madhu, and S. Vega, Enhanced conversion of triple to single-quantum coherence in the triple-quantum MAS NMR spectroscopy of spin-5/2 nuclei, Chem. Phys. Lett. 320, 448-456 (2000).

3. P. K. Madhu, A. Goldbourt, L. Frydman, and S. Vega, Fast radio-frequency amplitude modulation in MQMAS NMR: Theory and experiments, J. Chem. Phys. 112, 2377-2391 (2000).

4. P. K. Madhu, A. Goldbourt, L. Frydman, and S. Vega, Sensitivity enhancement of the MQMAS NMR experiment by fast amplitude modulation of the pulses, Chem. Phys. Lett. 307, 41-47 (1999).

5. A. Medek and L. Frydman, Quadrupolar and chemical shift tensors characterized by 2D MQMAS NMR spectroscopy, J. Magn. Reson. 138, 298-307 (1999).

6. L. Marinelli, A. Medek, and L. Frydman, Composite pulse excitation schemes for MQMAS NMR of half-integer quadrupolar spins, J. Magn. Reson. 132, 88-95 (1998).

7. F. H. Larsen and N. C. Nielsen, Effects of finite RF pulses and sample spinning speed in multiple-quantum magic-angle spinning (MQ-MAS) and multiple-quantum quadrupolar CarrPurcell-Meiboom-Gill magic-angle spinning (MQ-QCPMG-MAS) nuclear magnetic resonance of half-integer quadrupolar nuclei, J. Phys. Chem. A 103, 10825-10832 (1999).

8. T. Vosegaard, F. H. Larsen, H. J. Jakobsen, P. D. Ellis, and N. C. Nielsen, Sensitivity-enhanced multiple-quantum MAS NMR of half-integer quadrupolar nuclei, J. Am. Chem. Soc. 119, 90559056 (1997).

9. S. Steuernagel, A new sequence for the MQMAS/HETCOR experiment, Solid State NMR 11, 197-201 (1998).

10. S. H. Wang, S. M. De Paul, and L. M. Bull, High-resolution heteronuclear correlation between quadrupolar and spin-1/2 nuclei using MQ MAS, J. Magn. Reson. 125, 364-368 (1997). 
11. M. Pruski, C. Fernandez, D. P. Lang, and J.-P. Amoureux, Measurement of interatomic connectivities in molecular sieves using MQMAS-based methods, Catal. Today 49, 401-409 (1999).

12. M. Pruski, A. Bailly, D. P. Lang, J.-P. Amoureux, and C. Fernandez, Studies of heteronuclear dipolar interactions between spin-1/2 and quadrupolar nuclei by using REDOR during multiple quantum evolution, Chem. Phys. Lett. 307, 35-40 (1999).

13. T. Mildner, M. E. Smith, and R. Dupree, 2D five quantum MAS NMR using rotationally induced coherence transfer, Chem. Phys. Lett. 306, 297-302 (1999).

14. T. Mildner, M. E. Smith, and R. Dupree, Rotationally induced triple quantum coherence excitation in MAS NMR spectroscopy of I = 5/2 spins, Chem. Phys. Lett. 301, 389-394 (1999).

15. S. E. Ashbrook and S. Wimperis, Multiple-quantum cross-polarization and two-dimensional MQMAS NMR of quadrupolar nuclei, J. Magn. Reson. 147, 238-249 (2000).

16. S. E. Ashbrook, S. P. Brown, and S. Wimperis, Multiple-quantum cross-polarization in MAS NMR of quadrupolar nuclei, Chem. Phys. Lett. 288, 509-517 (1998).

17. S. P. Brown, S. E. Ashbrook, and S. Wimperis, ${ }^{27} \mathrm{Al}$ MQ-MAS NMR study of the thermal transformation between the microporous aluminum methylphosphonates AlMePO- $\beta$ and AlMePO- $\alpha$, J. Phys. Chem. B 103, 812-817 (1999).

18. T. Vosegaard, D. Massiot, and P. J. Grandinetti, Sensitivity enhancements in MQ-MAS NMR of spin-5/2 nuclei using modulated RF mixing pulses, Chem. Phys. Lett. 326, 454-460 (2000).

19. T. Vosegaard, P. Florian, P. J. Grandinetti, and D. Massiot, Pure absorption-mode spectra using a modulated RF mixing period in MQMAS experiments, J. Magn. Reson. 143, 217-222 (2000).

20. V. Lacassagne, P. Florian, V. Montouillout, C. Gervais, F. Babonneau, and D. Massiot, Resolution enhancement in solid-state MQ-MAS experiments achieved by composite decoupling, Magn. Reson. Chem. 36, 956-959 (1998).

21. S. Ding and C. A. McDowell, MQ-MAS NMR spectroscopy of spin-3/2 quadrupolar spin systems using shaped pulses, J. Magn. Reson. 135, 61-69 (1998).

22. S. Ding and C. A. McDowell, Shaped pulse excitation in MQ MAS spectroscopy of half-integer quadrupole spin systems, Chem. Phys. Lett. 270, 81-86 (1997).

23. J.-P. Amoureux and C. Fernandez, Triple, quintuple and higher order multiple quantum MAS NMR of quadrupolar nuclei, Solid State NMR 10, 211-223 (1998).

24. J.-P. Amoureux and C. Fernandez, Erratum to "Triple, quintuple and higher order multiple quantum MAS NMR of quadrupolar nuclei” [Solid State NMR 10 (1998), 211-223], Solid State NMR 16, 339-343 (2000).

25. D. Iuga, H. Schäfer, R. Verhagen, and A. P. M. Kentgens, Population and coherence transfer induced by double frequency sweeps in half-integer quadrupolar spin systems, J. Magn. Reson. 147, 192-209 (2000).

26. G. Wu, Decoupling-induced recoupling in MQMAS NMR spectra of quadrupolar nuclei, Chem. Phys. Lett. 322, 513-519 (2000).

27. G. Wu and K. Yamada, Residual dipolar couplings in MAS and MQMAS NMR spectra of quadrupolar nuclei, Chem. Phys. Lett. 313, 519-524 (1999).

28. G. Wu, S. Kroeker, R. E. Wasylishen, and R. G. Griffin, Indirect spin-spin coupling in MQMAS NMR spectra of quadrupolar nuclei, J. Magn. Reson. 124, 237-239 (1997).

29. K. J. Pike, R. P. Malde, S. E. Ashbrook, J. McManus, and S. Wimperis, Multiple-quantum MAS NMR of quadrupolar nuclei: Do five-, seven- and nine-quantum experiments yield higher resolution than the three-quantum experiment? Solid State NMR 16, 203-215 (2000).

30. J. McManus, R. Kemp-Harper, and S. Wimperis, Second-order quadrupolar-dipolar broadening in two-dimensional MQMAS NMR, Chem. Phys. Lett. 311, 292-298 (1999).

31. S. Caldarelli and F. Ziarelli, Spectral editing of solid-state MAS NMR spectra of half-integer quadrupolar nuclei, J. Am. Chem. Soc. 122, 12015-12016 (2000).

32. Z. Gan, Isotropic NMR spectra of half-integer quadrupolar nuclei using satellite transitions and MAS, J. Am. Chem. Soc. 122, 3242-3243 (2000). 
33. T. S. Mahesh, T. G. Ajithkumar, C. S. Nagaraja, G. Bodenhausen, and A. Kumar, Suppression of sidebands in two-dimensional exchange and MQMAS spectrocopies in solids by variable-speed magic-angle sample spinning, Chem. Phys. Lett. 319, 278-282 (2000).

34. T. Charpentier and J. Virlet, Triple quantum MQMAS spectroscopy of ${ }^{59} \mathrm{Co}(I=7 / 2)$ in $\mathrm{Na}_{3} \mathrm{Co}\left(\mathrm{NO}_{2}\right)_{6}$ and trans-Co[(en $\left.\left.\mathrm{en}_{2}\right)\left(\mathrm{NO}_{2}\right)_{2}\right] \mathrm{NO}_{3}$ interplay between the quadrupole coupling and anisotropic shielding tensors, Solid State NMR 12, 227-242 (1998).

35. T. Charpentier, C. Fermon, and J. Virlet, Numerical and theoretical analysis of multiquantum MAS experiments, J. Chem. Phys. 109, 3116-3130 (1998).

36. T. Charpentier, C. Fermon, and J. Virlet, Efficient time propagation technique for MAS NMR simulation: Application to quadrupolar nuclei, J. Magn. Reson. 132, 181-190 (1998).

37. S. Ding and C. A. McDowell, Quantification of MQMAS spectra of solids containing quadrupolar nuclei, Chem. Phys. Lett. 307, 215-219 (1999).

38. K. H. Lim and C. P. Grey, Analysis of the anisotropic dimension in the RIACT (II) MQ-MAS NMR experiment for $I=3 / 2$ nuclei, Solid State NMR 13, 101-112 (1998).

39. M. J. Duer and A. J. Painter, Correlating quadrupolar nuclear spins: A MQMAS approach, Chem. Phys. Lett. 313, 763-770 (1999).

40. M. E. Smith and E. R. H. van Eck, Recent advances in experimental solid state NMR methodology for half-integer spin quadrupolar nuclei, Prog. Nucl. Magn. Reson. Spectrosc. 34, 159-201 (1999).

41. P. R. Bodart, Distributions of the quadrupolar and isotropic chemical shift interactions in 2D MQMAS NMR spectra, J. Magn. Reson. 133, 207-209 (1998).

42. J. Quartararo, M. Guelton, M. Rigole, J.-P. Amoureux, C. Fernandez, and J. Grimblot, Sol-gel synthesis of alumina modified by phosphorus: A solid state NMR characterization study, J. Mater. Chem. 9, 2637-2646 (1999).

43. M. Schulz, M. Tiemann, M. Fröba, and C. Jäger, NMR characterization of mesostructured aluminophosphates, J. Phys. Chem. B 104, 10473-10481 (2000).

44. G. Mali, J.-P. Amoureux, and V. Kaucic, ${ }^{27} \mathrm{Al} \rightarrow{ }^{31} \mathrm{P} 3 \mathrm{QMAS} /$ HETCOR experiment in aluminophosphate molecular sieves, Phys. Chem. Chem. Phys. 2, 5737-5742 (2000).

45. P. R. Bodart, J.-P. Amoureux, M. Pruski, A. Bailly, and C. Fernandez, Applications of ${ }^{27} \mathrm{Al}$ MQMAS NMR to aluminophosphate molecular sieves, Magn. Reson. Chem. 37, S69-S74 (1999).

46. S. Caldarelli, A. Meden, and A. Tuel, Solid-state NMR study of the microporous aluminophosphate $\mathrm{AlPO}_{4}-41$, J. Phys. Chem. B 103, 5477-5487 (1999).

47. F. Taulelle, M. Pruski, J.-P. Amoureux, D. Lang, A. Bailly, C. Huguenard, M. Haouas, C. Gérardin, T. Loiseau, and G. Ferey, Isomerization of the prenucleation building unit during crystallization of $\mathrm{AlPO}_{4}$-CJ2: An MQMAS, CP-MQMAS, and HETCOR NMR study, J. Am. Chem. Soc. 121, 12148-12153 (1999).

48. P. Sarv, B. Wichterlova, and J. Cejka, Multinuclear MQMAS NMR study of $\mathrm{NH}_{4} / \mathrm{Na}$-Ferrierites, $J$. Phys. Chem. B 102, 1372-1378 (1998).

49. U.-T. Pingel, J.-P. Amoureux, T. Anupold, F. Bauer, H. Ernst, C. Fernandez, D. Freude, and A. Samoson, High-field ${ }^{17} \mathrm{O}$ NMR studies of the SiOAl bond in solids, Chem. Phys. Lett. 294, 345-350(1998).

50. P. R. Bodart, J. Parmentier, R. K. Harris, and D. P. Thompson, Aluminium environments in mullite and amorphous sol-gel precursor examined by ${ }^{27} \mathrm{Al}$ triple-quantum MAS NMR, J. Phys. Chem. Solids 60, 223-228 (1999).

51. R. D. Gougeon, P. R. Bodart, R. K. Harris, D. M. Kolonia, D. E. Petrakis, and P. J. Pomonis, Solid-state NMR study of mesoporous phosphoro-vanado-aluminas, Phys. Chem. Chem. Phys. 2, 5286-5292 (2000).

52. M. W. Anderson, J. R. Agger, D. P. Luigi, A. K. Baggaley, and J. Rocha, Cation sites in ETS10: ${ }^{23} \mathrm{Na}$ 3Q MAS NMR and lattice energy minimisation calculations, Phys. Chem. Chem. Phys. 1, 2287-2292 (1999).

53. J. A. van Bokhoven, D. C. Koningsberger, P. Kunkeler, H. van Bekkum, and A. P. M. Kentgens, Stepwise dealumination of zeolite beta at specific T-sites observed with ${ }^{27} \mathrm{Al}$ MAS and ${ }^{27} \mathrm{Al} \mathrm{MQ}$ MAS NMR, J. Am. Chem. Soc. 122, 12842-12847 (2000). 
54. A. Burton, M. Feuerstein, R. F. Lobo, and J. C. C. Chan, Characterization of cancrinite synthesized in 1,3-butanediol by Rietveld analysis of powder neutron diffraction data and solid-state ${ }^{23} \mathrm{Na}$ NMR spectroscopy, Microporous Mesoporous Mater. 30, 293-305 (1999).

55. L. J. Smith, H. Eckert, and A. K. Cheetham, Site preferences in the mixed cation zeolite, Li, Na-Chabazite: A combined solid-state NMR and neutron diffraction study, J. Am. Chem. Soc. 122, 1700-1708 (2000).

56. B. H. Wouters, T. Chen, A. M. Goossens, J. A. Martens, and P. J. Grobet, Determination of the $\mathrm{Al}^{\mathrm{T} 1} / \mathrm{Al}^{\mathrm{T} 2}$ ratio in MAZ zeolites using line shapes of MQMAS NMR, J. Phys. Chem. B 103, 8093-8096 (1999).

57. P. Lentz, A. P. Carvalho, L. Delevoye, C. Fernandez, J.-P. Amoureux, and L. B.Nagy, Characterization of offretite during hydrothermal treatment by high-resolution solid-state ${ }^{29} \mathrm{Si}$ MAS NMR and ${ }^{27} \mathrm{Al}$ triple-quantum MAS NMR spectroscopy, Magn. Reson. Chem. 37, S55-S62 (1999).

58. T. H. Chen, B. H. Wouters, and P. J. Grobet, Enhanced resolution of aluminum and proton sites in the molecular sieves SAPO-37 by ${ }^{27} \mathrm{Al}$ MQMAS and ${ }^{1} \mathrm{H}$ spin echo editing NMR, J. Phys. Chem. B 103, 6179-6184 (1999).

59. K. H. Lim and C. P. Grey, Characterization of extra-framework cation positions in zeolites NaX and NaY with very fast ${ }^{23} \mathrm{Na}$ MAS and MQMAS NMR spectroscopy, J. Am. Chem. Soc. 122, 9768 9780 (2000).

60. K. N. Hu and L. P. Hwang, The influence of adsorbed molecules on Na-sites in NaY zeolite investigated by triple-quantum ${ }^{23}$ Na MAS NMR spectroscopy, Solid State NMR 12, 211-220 (1998).

61. B. H. Wouters, T.-H. Chen, and P. J. Grobet, Steaming of zeolite Y: Formation of transient Al species, J. Phys.Chem. B 105, 1135-1139 (2001).

62. J. A. van Bokhoven, A. L. Roest, D. C. Koningsberger, J. T. Miller, G. H. Nachtegaal, and A. P. M. Kentgens, Changes in structural and electronic properties of the zeolite framework induced by extraframework $\mathrm{Al}$ and $\mathrm{La}$ in $\mathrm{H}-\mathrm{USY}$ and $\mathrm{La}(\mathrm{x}) \mathrm{NaY}$ : $\mathrm{A}{ }^{29} \mathrm{Si}$ and ${ }^{27} \mathrm{Al}$ MAS NMR and ${ }^{27} \mathrm{Al}$ MQ MAS NMR study, J. Phys. Chem. B 104, 6743-6754 (2000).

63. C. A. Fyfe, J. L. Bretherton, and L. Y. Lam, Detection of the 'invisible aluminium' and characterisation of the multiple aluminium environments in zeolite USY by high-field solid-state NMR, J. Chem. Soc. Chem. Commun. 1575-1576 (2000).

64. A. P. M. Kentgens, D. Iuga, M. Kalwei, and H. Koller, Direct observation of Bronsted acidic sites in dehydrated zeolite H-ZSM5 using DFS-enhanced ${ }^{27}$ Al MQMAS NMR spectroscopy, J. Am. Chem. Soc. 123, 2925-2926 (2001).

65. G. Engelhardt, A. P. M. Kentgens, H. Koller, and A. Samoson, Strategies for extracting NMR parameters from ${ }^{23} \mathrm{Na}$ MAS, DOR, and MQMAS spectra: A case study for $\mathrm{Na}_{4} \mathrm{P}_{2} \mathrm{O}_{7}$, Solid State NMR 15, 171-180 (1999).

66. A. P. M. Kentgens and R. Verhagen, Advantages of double frequency sweeps in static, MAS and MQMAS NMR of spin $I=3 / 2$ nuclei, Chem. Phys. Lett. 300, 435-443 (1999).

67. T. Anupold, A. Reinhold, P. Sarv, and A. Samoson, A comparison of double rotation and MQ-MAS spectra, Solid State NMR 13, 87-91 (1998).

68. C. A. Fyfe, H. Meyer zu Altenschildesche, and J. Skibsted, Characterization of $\mathrm{Na}_{5} \mathrm{P}_{3} \mathrm{O}_{10}$ polymorphs by ${ }^{23} \mathrm{Na}$ MAS, ${ }^{23} \mathrm{Na}$ MQMAS, and ${ }^{31} \mathrm{P}$ MAS NMR spectroscopy, Inorg. Chem. 38, 84-92 (1999).

69. S. R. Jansen, H. T. Hintzen, R. Metselaar, J. W. de Haan, L. J. M. van de Ven, A. P. M. Kentgens, and G. H. Nachtegaal, Multiple quantum ${ }^{27} \mathrm{Al}$ MAS NMR spectroscopic study of $\mathrm{SrAl}_{12} \mathrm{O}_{19}$ : Identification of a ${ }^{27} \mathrm{Al}$ resonance from a well-defined $\mathrm{AlO}_{5}$ site, J. Phys. Chem. B 102, 5969-5976 (1998).

70. L. B. Alemany, S. Steuernagel, J.-P. Amoureux, R. L. Callender, and A. R. Barron, Very fast MAS and MQMAS NMR studies of the spectroscopically challenging minerals kyanite and andalusite on 400, 500, and $800 \mathrm{MHz}$ spectrometers, Solid State NMR 14, 1-18 (1999).

71. J. Rocha, Direct observation of highly distorted hexa-coordinated aluminium in andalusite by very fast ${ }^{27}$ Al MAS NMR, J. Chem. Soc. Chem. Commun. 2489-2490 (1998). 
72. S. E. Ashbrook, A. J. Berry, and S. Wimperis, Three- and five-quantum ${ }^{17} \mathrm{O}$ MAS NMR of forsterite $\mathrm{Mg}_{2} \mathrm{SiO}_{4}$, Am. Mineral. 84, 1191-1194 (1999).

73. J. Rocha, Single- and triple-quantum ${ }^{27} \mathrm{Al}$ MAS NMR study of the thermal transformation of Kaolinite, J. Phys. Chem. B 103, 9801-9804 (1999).

74. L. B. Alemany, R. L. Callender, A. R. Barron, S. Steuernagel, D. Iuga, and A. P. M. Kentgens, Single-pulse MAS, selective Hahn echo MAS, and 3QMAS NMR studies of the mineral Zoisite at 400, 500, 600, and $800 \mathrm{MHz}$ : Exploring the limits of Al NMR detectability, J. Phys. Chem. B 104, $11612-11616$ (2000).

75. D. Iuga, S. Simon, E. de Boer, and A. P. M. Kentgens, A nuclear magnetic resonance study of amorphous and crystalline lanthanum-aluminates, J. Phys. Chem. B 103, 7591-7598 (1999).

76. P. Faucon, J. C. Petit, T. Charpentier, and J. F. Jacquinot, Silicon substitution for aluminum in calcium silicate hydrates, J. Am. Ceram. Soc. 82, 1307-1312 (1999).

77. P. Faucon, T. Charpentier, D. Bertrandie, A. Nonat, J. Virlet, and J. C. Petit, Characterization of calcium aluminate hydrates and related hydrates of cement pastes by ${ }^{27} \mathrm{Al}$ MQ-MAS NMR, Inorg. Chem. 37, 3726-3733 (1998).

78. J. Rocha, M. del Arco, V. Rives, and M. A. Ulibarri, Reconstruction of layered double hydroxides from calcined precursors: A powder XRD and ${ }^{27}$ Al MAS NMR study, J. Mater. Chem. 9, 2499-2503 (1999).

79. D. Rovnyak, M. Baldus, G. Wu, N. V. Hud, J. Feigon, and R. G. Griffin, Localization of ${ }^{23} \mathrm{Na}^{+}$in a DNA quadruplex by high-field solid-state NMR, J. Am. Chem. Soc. 122, 11423-11429 (2000).

80. A. Wong and G. Wu, Solid-state ${ }^{23} \mathrm{Na}$ NMR of sodium complexes with crown ethers, cryptands, and naturally occurring antibiotic ionophores: A direct probe to sodium-binding sites, J. Phys. Chem. A 104, 11844-11852 (2000).

81. C. V. Grant, V. Frydman, and L. Frydman, Solid-state ${ }^{25} \mathrm{Mg}$ NMR of a magnesium(II) adensosine 5'-triphosphate complex, J. Am. Chem. Soc. 122, 11743-11744 (2000).

82. J. Ashenhurst, S. Wang, and G. Wu, Probing the origin of disorder in polynuclear aluminum 7-azaindolyl complexes by ${ }^{27} \mathrm{Al}$ MQ MAS NMR, J. Am. Chem. Soc. 122, 3528-3529 (2000).

83. J. C. C. Chan, M. Bertmer, and H. Eckert, Sites connectivities in amorphous materials studied by double-resonance NMR of quadrupolar nuclei: High-resolution ${ }^{11} \mathrm{~B} \leftrightarrow{ }^{27} \mathrm{Al}$ spectroscopy of aluminoborate glasses, J. Am. Chem. Soc. 121, 5238-5248 (1999).

84. L. Zùchner, J. C. C. Chan, W. Müller-Warmuth, and H. Eckert, Short-range order and site connectivities in sodium aluminoborate glasses. I. Quantification of local environments by high-resolution ${ }^{11} \mathrm{~B},{ }^{23} \mathrm{Na}$, and ${ }^{27} \mathrm{Al}$ solid-state NMR, J. Phys. Chem. B 102, 4495-4506 (1998).

85. J. C. C. Chan, High-resolution heteronuclear correlation between quadrupolar nuclei, J. Magn. Reson. 140, 487-490 (1999).

86. J. M. Egan and K. T. Mueller, Detection and identification of corrosion products of sodium aluminoborosilicate glasses by ${ }^{23} \mathrm{Na}$ MQMAS and ${ }^{1} \mathrm{H} \rightarrow{ }^{23} \mathrm{Na}$ CPMAS NMR, J. Phys. Chem. B 104, 9580-9586 (2000).

87. S. K. Lee and J. F. Stebbins, The structure of aluminosilicate glasses: High-resolution ${ }^{17} \mathrm{O}$ and ${ }^{27} \mathrm{Al}$ MAS and 3QMAS NMR study, J. Phys. Chem. B 104, 4091-4100 (2000).

88. J. F. Stebbins, S. K. Lee, and J. V. Oglesby, Al-O-Al oxygen sites in crystallines aluminates and aluminosilicate glasses: High-resolution oxygen-17 NMR results, Am. Mineral. 84, 983-986 (1999).

89. S. Wang and J. F. Stebbins, MQMAS ${ }^{17} \mathrm{O}$ NMR studies of borate, borosilicate, and boroaluminate glasses, J. Am. Ceram. Soc. 82, 1519-1528 (1999).

90. M. Witschas and $\mathrm{H}$. Eckert, ${ }^{31} \mathrm{P}$ and ${ }^{23} \mathrm{Na}$ solid-state NMR studies of cation dynamics in HT-sodium orthophosphate and the solid solutions $\left(\mathrm{Na}_{2} \mathrm{SO}_{4}\right)_{\mathrm{x}}-\left(\mathrm{Na}_{3} \mathrm{PO}_{4}\right)_{1-\mathrm{x}}$, J. Phys. Chem. A 103, 10764-10775 (1999).

91. F. Angeli, T. Charpentier, P. Faucon, and J.-C. Petit, Structural characterization of glass from the inversion of ${ }^{23} \mathrm{Na}$ and ${ }^{27} \mathrm{Al}$ 3Q-MAS NMR spectra, J. Phys. Chem. B 103, 10356-10364 (1999).

92. S.-J. Hwang, C. Fernandez, J.-P. Amoureux, J.-W. Han, J. Cho, S. W. Martin, and M. Pruski, Structural study of $\mathrm{xNa}_{2} \mathrm{~S}+(1-\mathrm{x}) \mathrm{B}_{2} \mathrm{~S}_{3}$ glasses and polycrystals by MQ-MAS NMR of ${ }^{11} \mathrm{~B}$ and ${ }^{23} \mathrm{Na}$, J. Am. Chem. Soc. 120, 7337-7346 (1998). 
93. J. Skibsted and H. J. Jakobsen, Variable-temperature ${ }^{87} \mathrm{Rb}$ magic-angle spinning NMR spectroscopy of inorganic rubidium salts, J. Phys. Chem. A 103, 7958-7971 (1999).

94. E. Lippmaa, A. Samoson, and M. Mägi, High-resolution ${ }^{27} \mathrm{Al}$ NMR of aluminosilicates, J. Am. Chem. Soc. 108, 1730-1735 (1986).

95. C. Bonhomme and J. Livage, Pictorial representation of anisotropy and macroscopic reorientations of samples in solid-state NMR: Second-order interactions, J. Phys. Chem. A 103, 460-477 (1999).

96. A. Medek, J. S. Harwood, and L. Frydman, Multiple-quantum MAS NMR: A new method for the study of quadrupolar nuclei in solids, J. Am. Chem. Soc. 117, 12779-12787 (1995).

97. D. Massiot, B. Touzo, D. Trumeau, J. P. Coutures, J. Virlet, P. Florian, and P. J. Grandinetti, Twodimensional MAS isotropic reconstruction sequences for quadrupolar nuclei, Solid State NMR 6, 73-83 (1996).

98. P. P. Man, Second-order quadrupole effects on Hahn echoes in fast-rotating solids at the magic angle, Phys. Rev. B 55, 8406-8424 (1997).

99. D. Freude, Quadrupolar nuclei in solid-state nuclear magnetic resonance, in "Encyclopedia of Analytical Chemistry" (R. A. Meyers, Ed.), pp. 12188-12224, Wiley, Chichester (2000).

100. E. L. Hahn, Spin echoes, Phys. Rev. 80, 580-594 (1950).

101. P. P. Man, Quadrupole couplings in nuclear magnetic resonance, general, in "Encyclopedia of Analytical Chemistry" (R. A. Meyers Ed.), pp. 12224-12265, Wiley, Chichester (2000).

102. J. C. C. Chan, Spin echoes in half-integer quadrupole systems, Concepts Magn. Reson. 11, 363-377 (1999).

103. Y. Dumazy, J.-P. Amoureux, and C. Fernandez, Theoretical and experimental study of quadrupolar echoes in solid state NMR, Mol. Phys. 90, 959-970 (1997).

104. P. R. Bodart, J.-P. Amoureux, Y. Dumazy, and R. Lefort, Theoretical and experimental study of quadrupolar echoes for half-integer spins in static solid-state NMR, Mol. Phys. 98, 1545-1551 (2000).

105. P. P. Man, Scaling and labeling the high-resolution isotropic axis of two-dimensional multiplequantum magic-angle-spinning spectra of half-integer quadrupole spins, Phys. Rev. B 58, 2764-2782 (1998).

106. M. Hanaya and R. K. Harris, Optimization of 2D MQ-MAS NMR experiments for $I=3 / 2$ nuclei on a moderate-field spectrometer, J. Phys. Chem. A 101, 6903-6910 (1997).

107. M. Hanaya and R. K. Harris, Effect of ${ }^{1} \mathrm{H}$-decoupling in 2D MQ-MAS NMR spectroscopy of ${ }^{23} \mathrm{Na}$ in a hydrous layered silicate, Solid State NMR 8, 147-151 (1997).

108. M. Hanaya and R. K. Harris, Two-dimensional ${ }^{23} \mathrm{Na}$ MQ MAS NMR study of layered silicates, $J$. Mater. Chem. 8, 1073-1079 (1998).

109. P. Florian, M. Gervais, A. Douy, D. Massiot, and J.-P. Coutires, A multi-nuclear multiple-field NMR study of the $\mathrm{Y}_{2} \mathrm{O}_{3}-\mathrm{Al}_{2} \mathrm{O}_{3}$ phase diagram, J. Phys. Chem. B 105, 379-391 (2001).

110. G. Wu, D. Rovnyak, B. Q. Sun, and R. G. Griffin, High-resolution multiple quantum MAS NMR spectroscopy of half-integer quadrupolar nuclei, Chem. Phys. Lett. 249, 210-217 (1996).

111. S. H. Wang, Z. Xu, J. H. Baltisberger, L. M. Bull, J. F. Stebbins, and A. Pines, MQ MAS and DAS NMR spectroscopy of quadrupolar nuclei, Solid State NMR 8, 1-16 (1997).

112. D. J. States, R. A. Haberkorn, and D. J. Ruben, A 2D nuclear Overhauser experiment with pure absorption phase in four quadrants, J. Magn. Reson. 48, 286-292 (1982).

113. P. J. Grandinetti, "RMN Program," Department of Chemistry, Ohio State University, Colombus, OH, 1996.

114. S. Ding and C. A. McDowell, Theoretical calculations of the CPMAS spectral lineshapes of halfinteger quadrupole systems, J. Magn. Reson. A 114, 80-87 (1995).

115. P. J. Barrie, Distorted powder lineshapes in ${ }^{27} \mathrm{Al} \mathrm{CP} / \mathrm{MAS}$ NMR spectroscopy of solids, Chem. Phys. Lett. 208, 486-490 (1993).

116. C. J. Turner and H. D. W. Hill, Artifacts in quadrature detection, J. Magn. Reson. 66, 410-421 (1986). 